Supporting information

\title{
Bioactive Secondary Metabolites Produced by the Oak Pathogen Diplodia corticola
}

Marco Masi, ${ }^{\dagger}$ Lucia Maddau, ${ }^{\ddagger}$ Benedetto Teodoro Linaldeddu, ${ }^{\ddagger}$ Alessio Cimmino, ${ }^{\dagger}$ Wanda D’Amico, ${ }^{\dagger}$ Bruno Scanu, ${ }^{\dagger}$ Marco Evidente, ${ }^{\dagger}$ Angela Tuzi, ${ }^{\dagger}$ and Antonio Evidente ${ }^{*}, \dagger$

${ }^{\dagger}$ Dipartimento di Scienze Chimiche, Università di Napoli Federico II, Complesso Universitario Monte Sant'Angelo, Via Cintia 4, 80126, Napoli, Italy

${ }^{ \pm}$Dipartimento di Agraria, Sezione di Patologia Vegetale ed Entomologia, Università degli Studi di Sassari, Viale Italia 39, 07100, Sassari, Italy 
${ }^{1} \mathrm{H}$ NMR spectrum of sapinofuranone C, 1

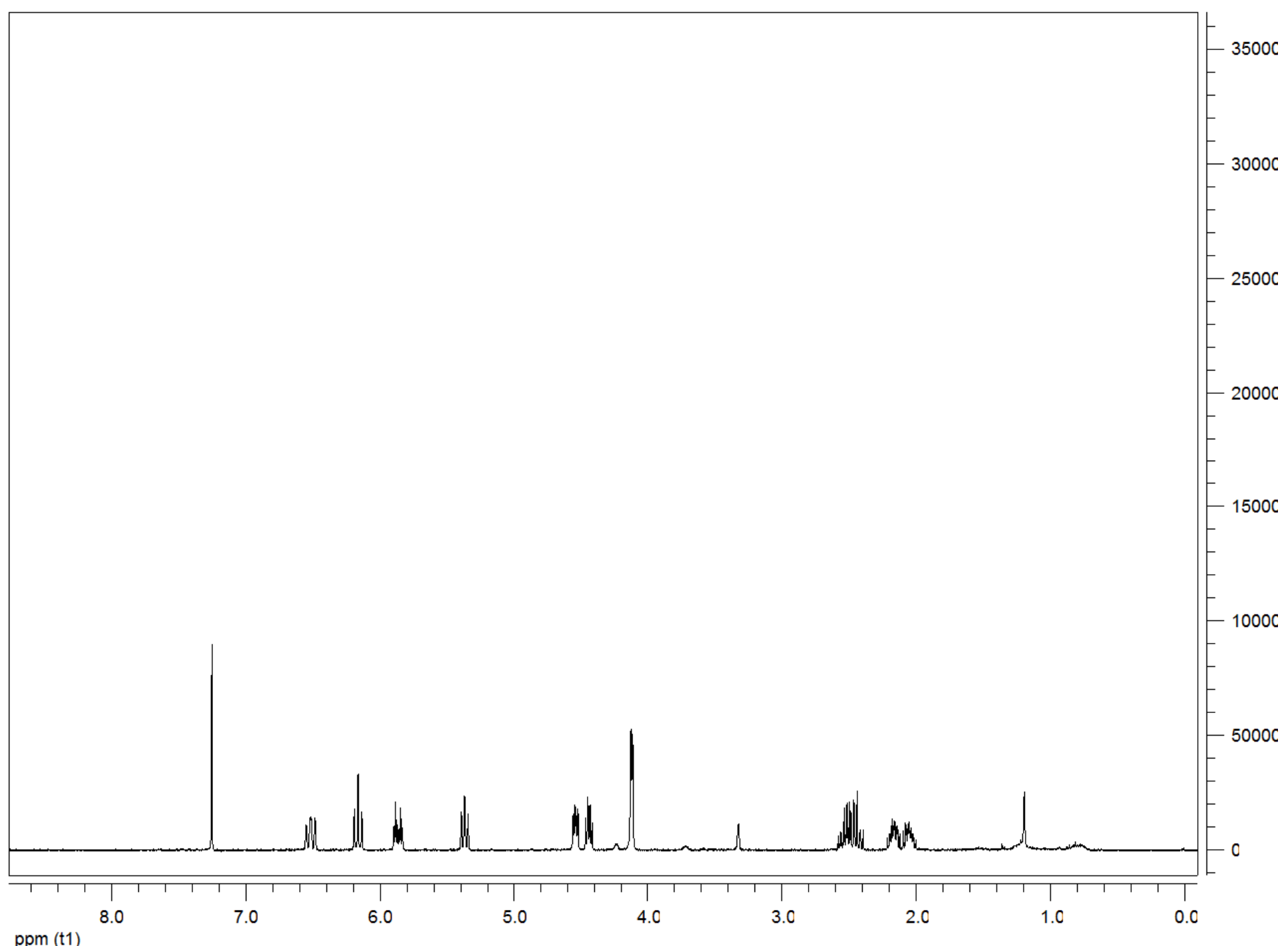


COSY spectrum of sapinofuranone $\mathrm{C}, \mathbf{1}$

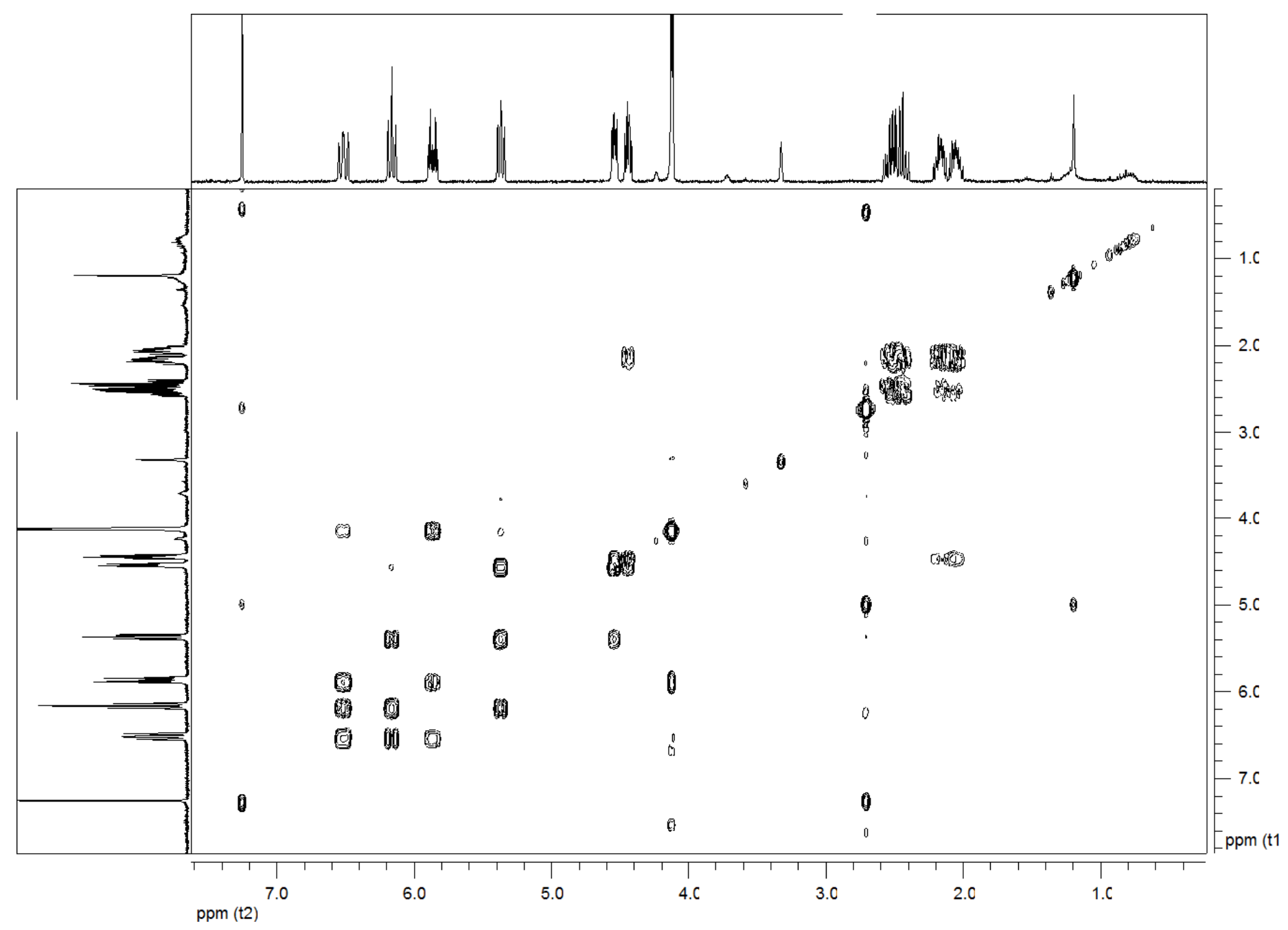


HSQC spectrum of sapinofuranone $\mathrm{C}, \mathbf{1}$

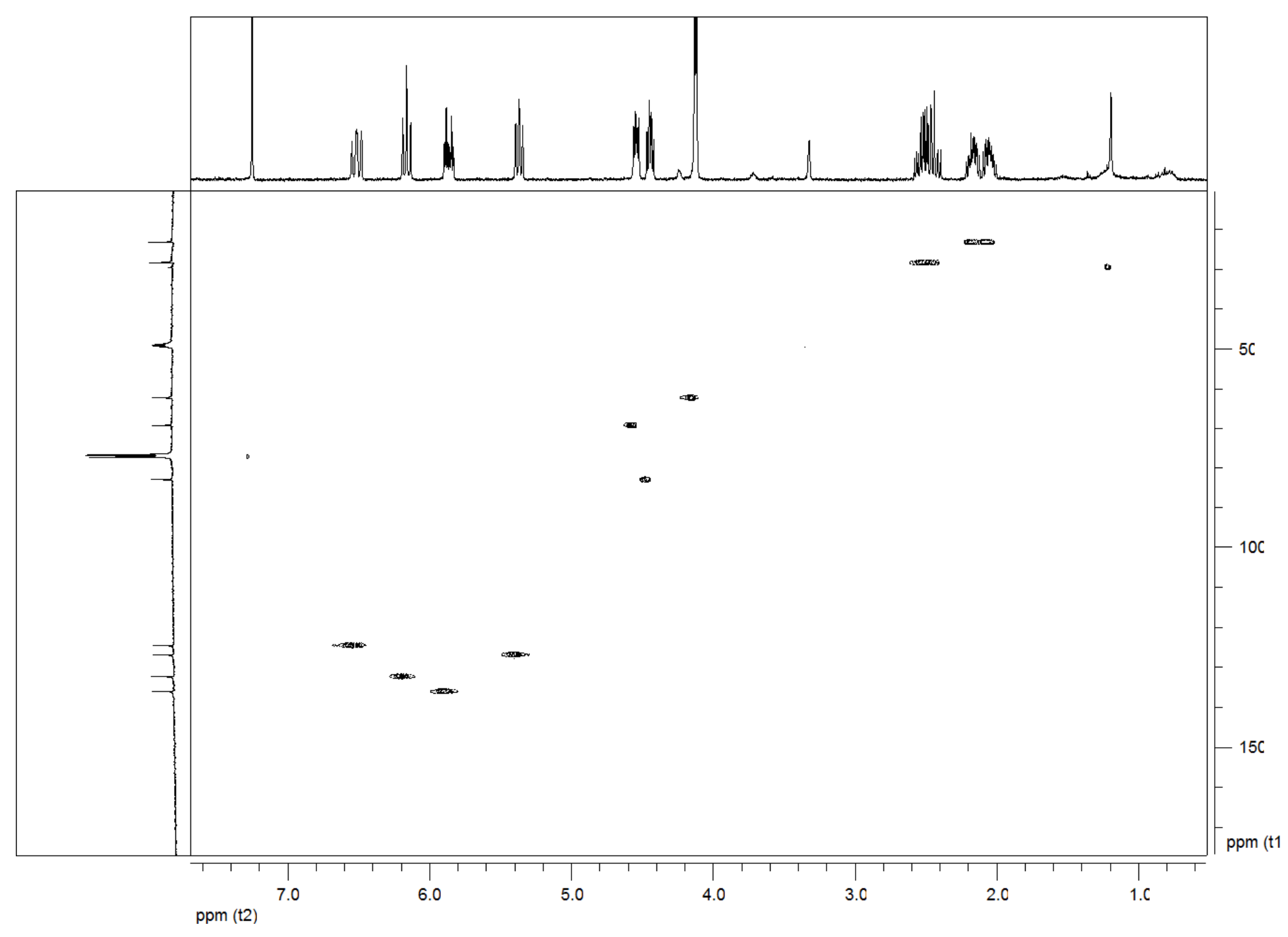


HMBC spectrum of sapinofuranone C, 1

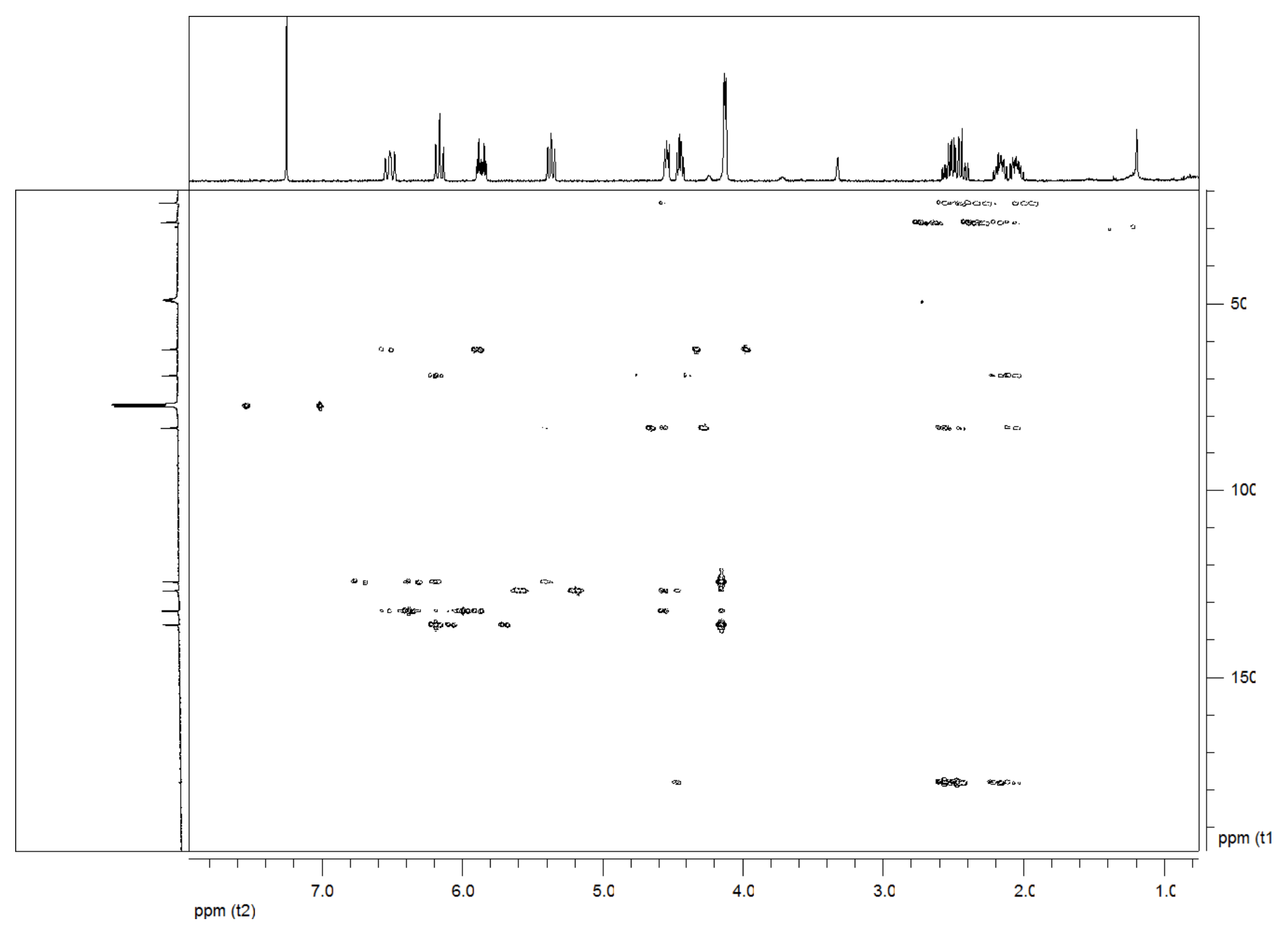


${ }^{13} \mathrm{C}$ NMR spectrum of sapinofuranone $\mathrm{C}, \mathbf{1}$

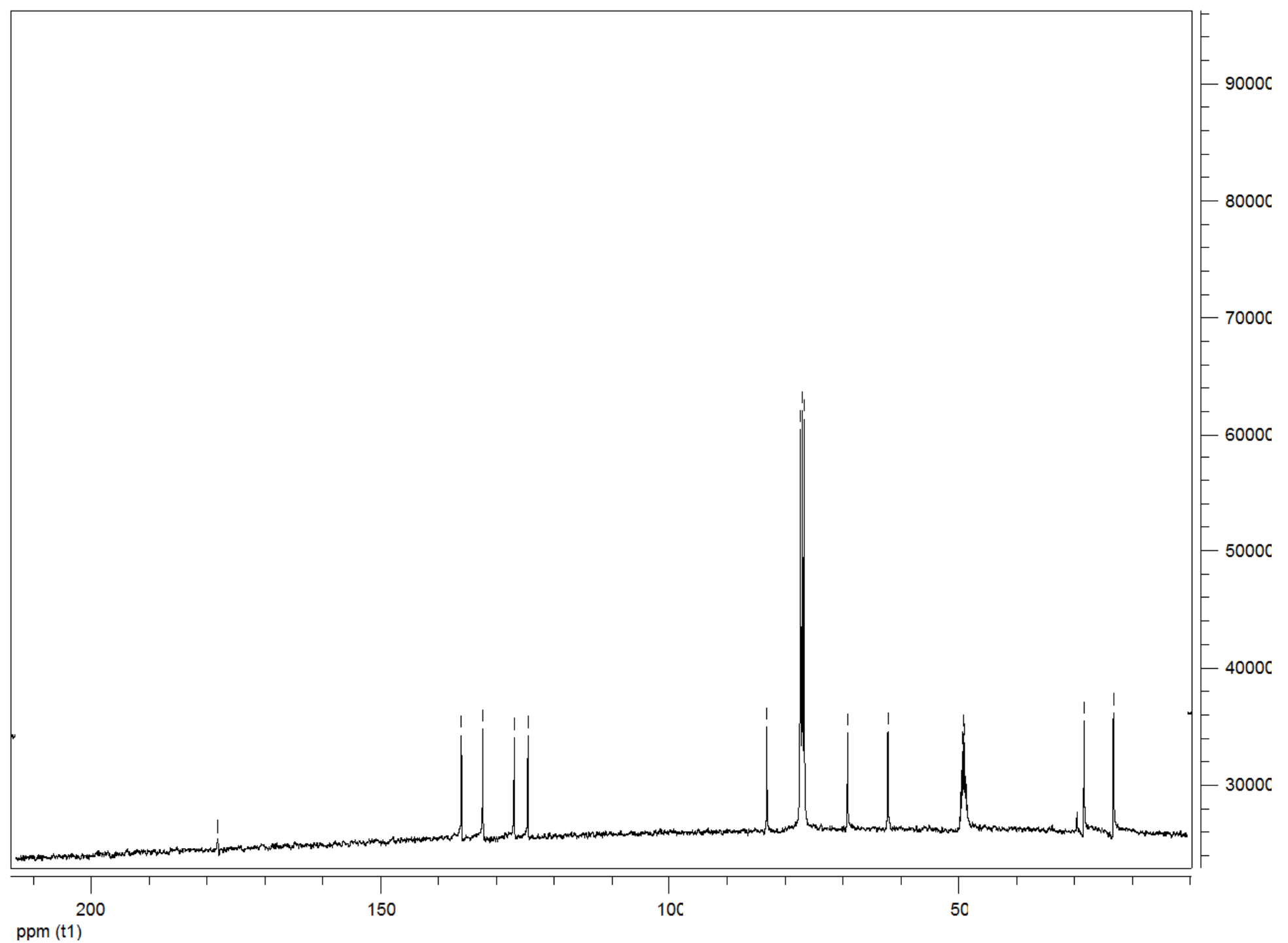

ppm (t1) 
NOESY spectrum of sapinofuranone $\mathrm{C}, \mathbf{1}$

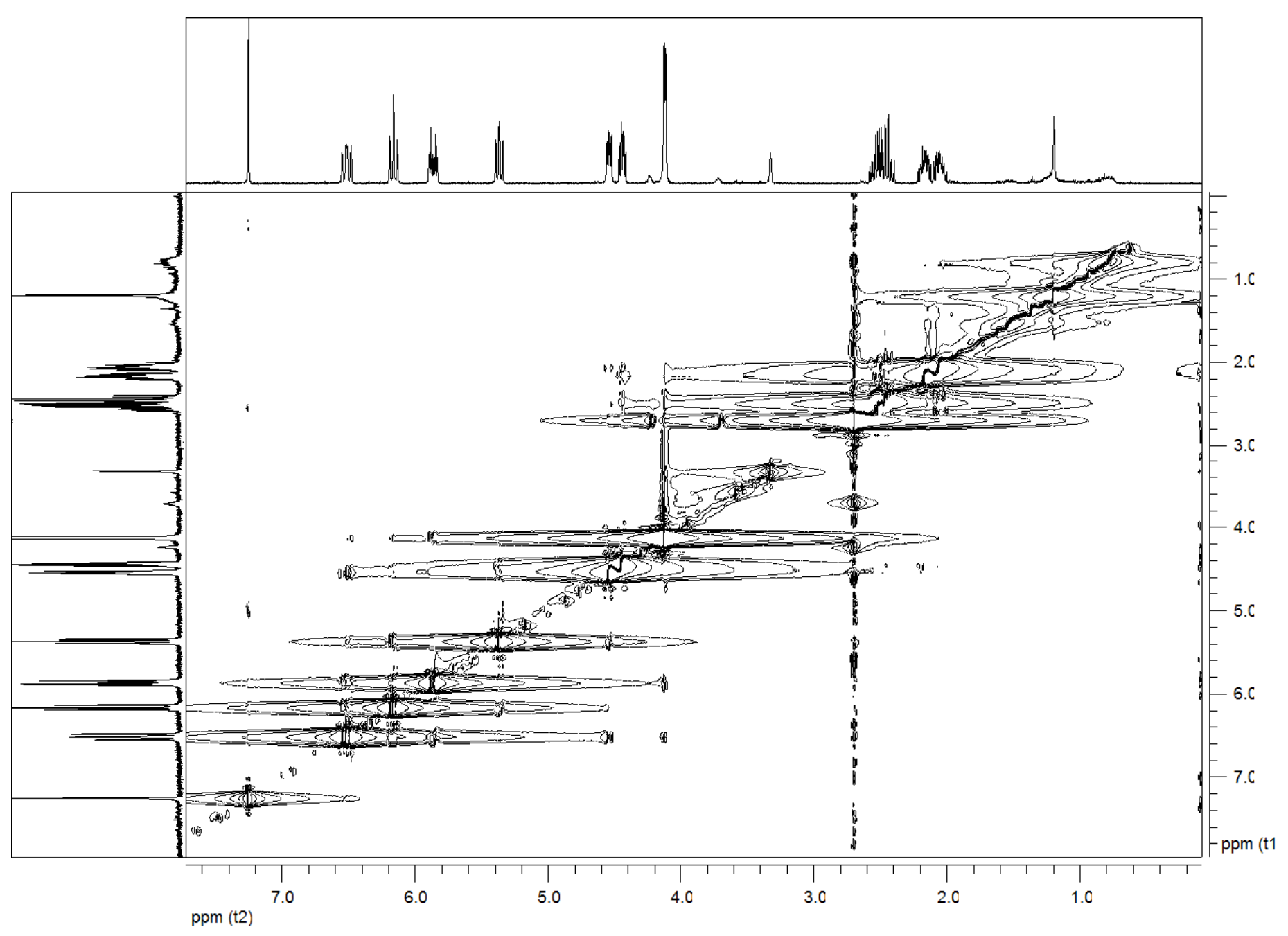


UV spectrum of sapinofuranone $\mathrm{C}, \mathbf{1}$

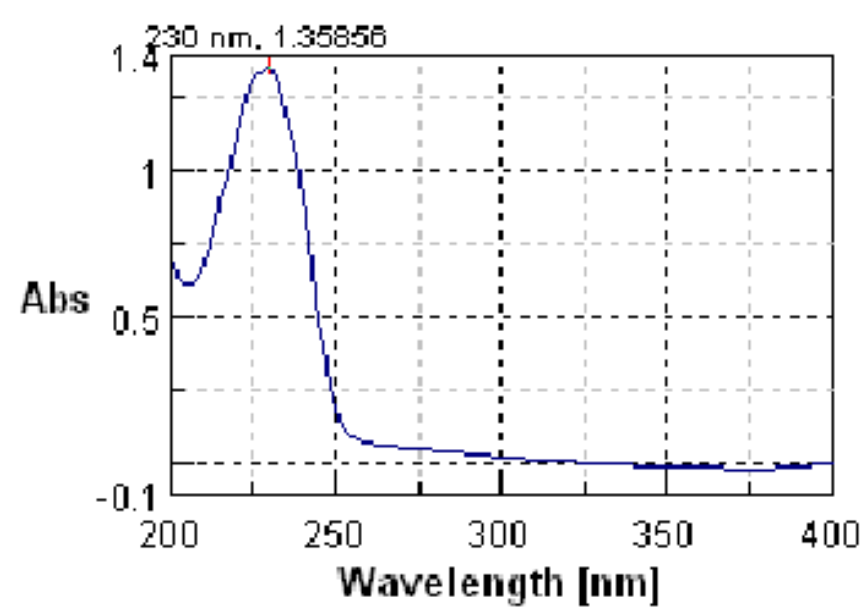


IR spectrum of sapinofuranone $\mathrm{C}, \mathbf{1}$

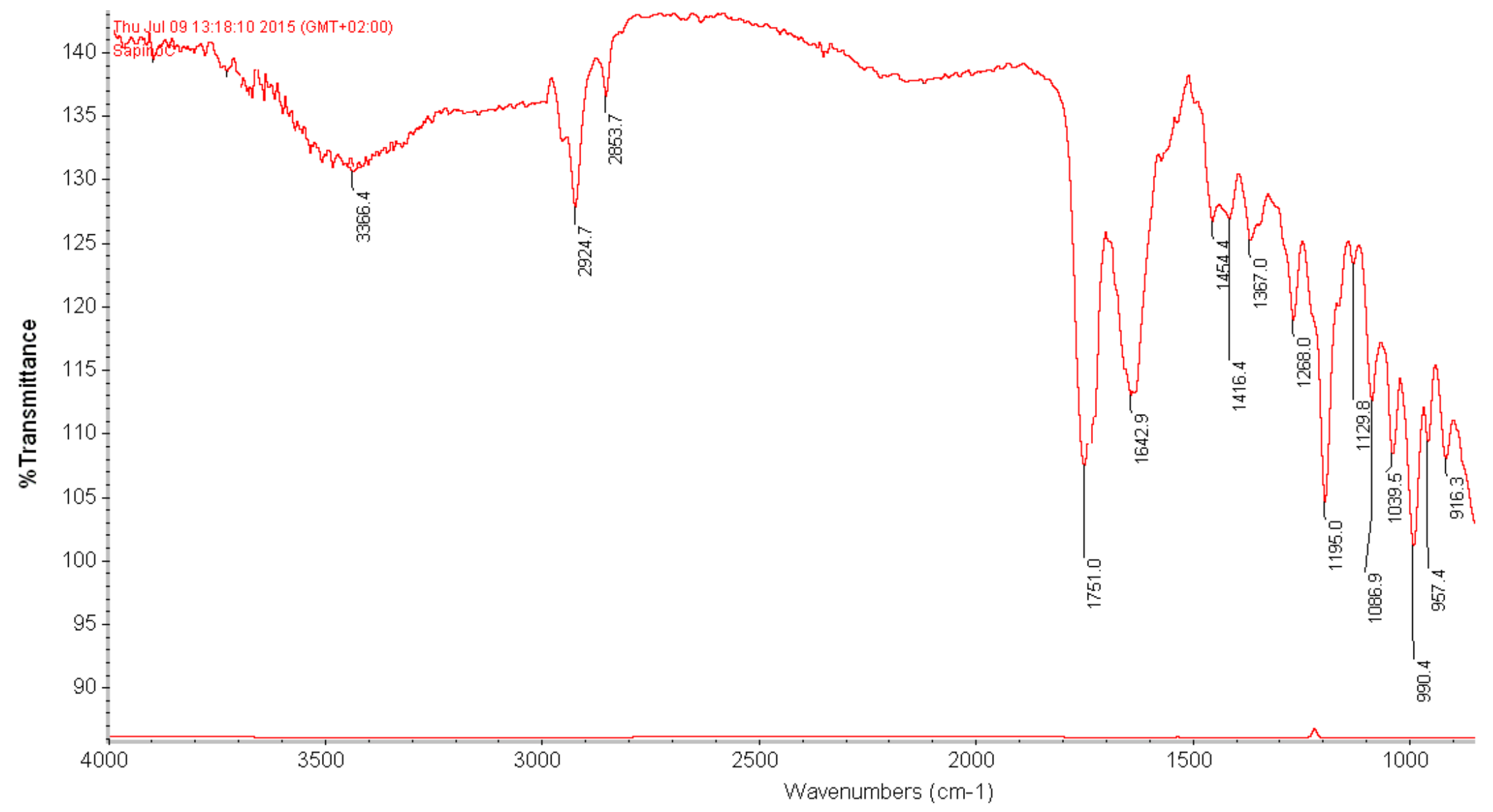


HR ESIMS (+) spectrum of sapinofuranone C, 1

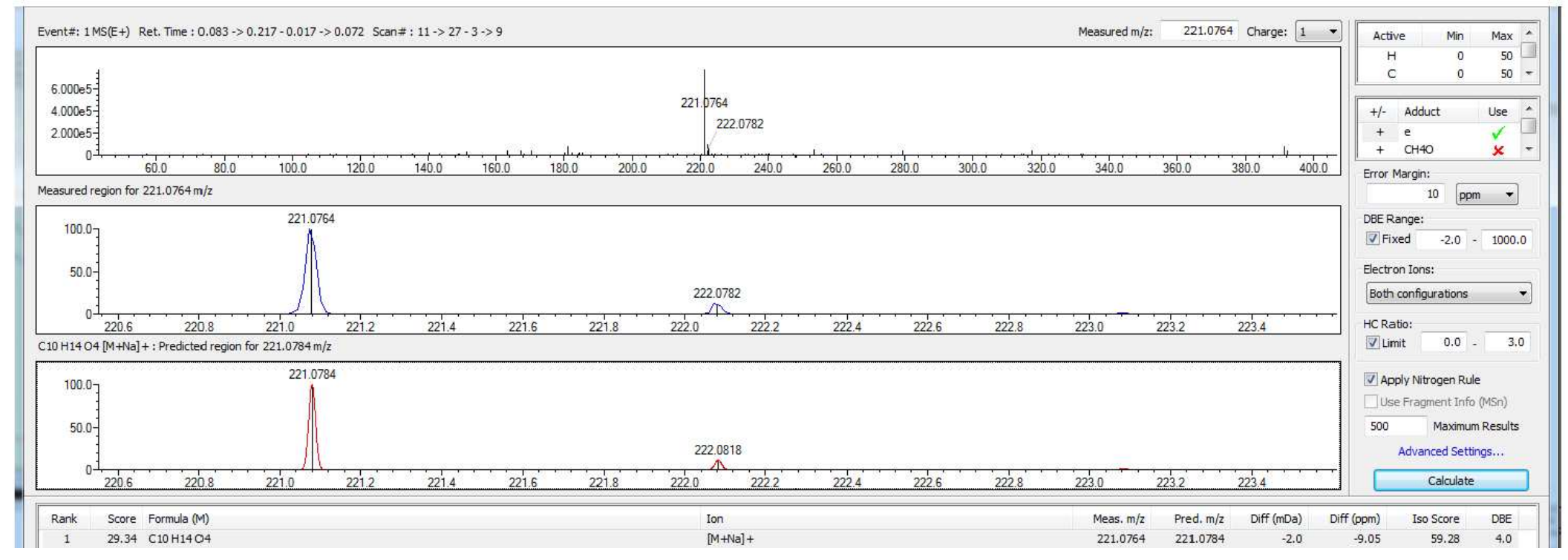


HR ESIMS (-) spectrum of sapinofuranone C, 1

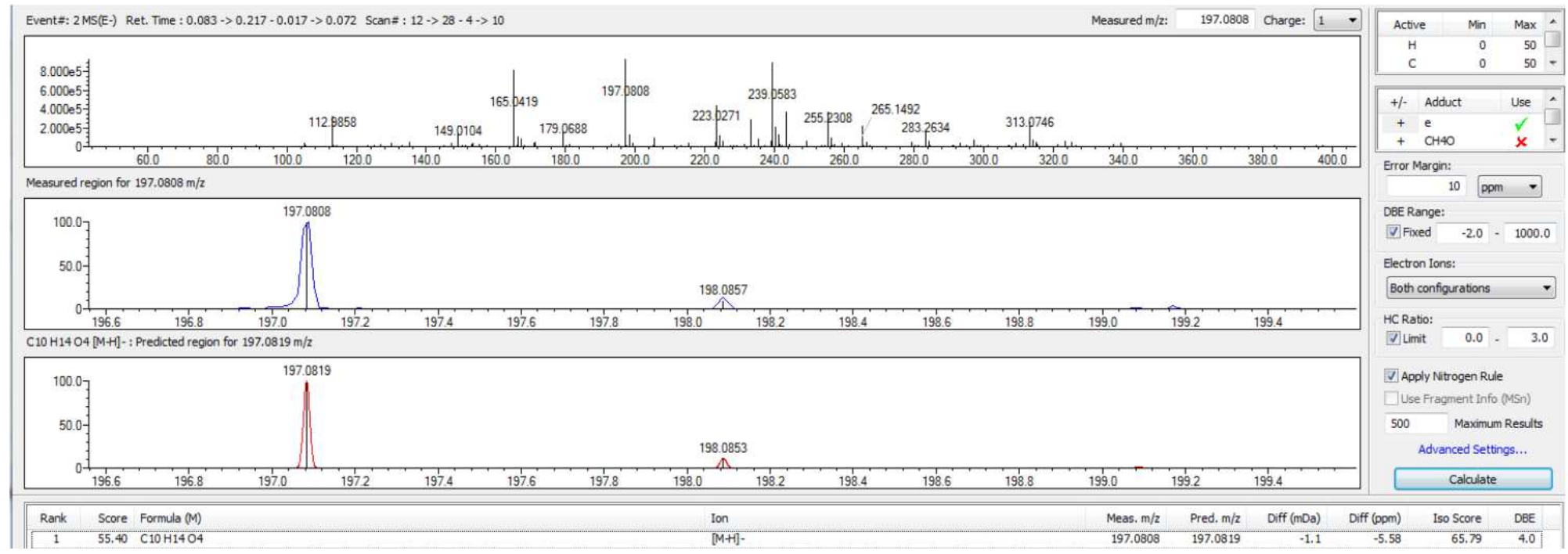


${ }^{1} \mathrm{H}$ NMR spectrum of diplopyrone B, 2

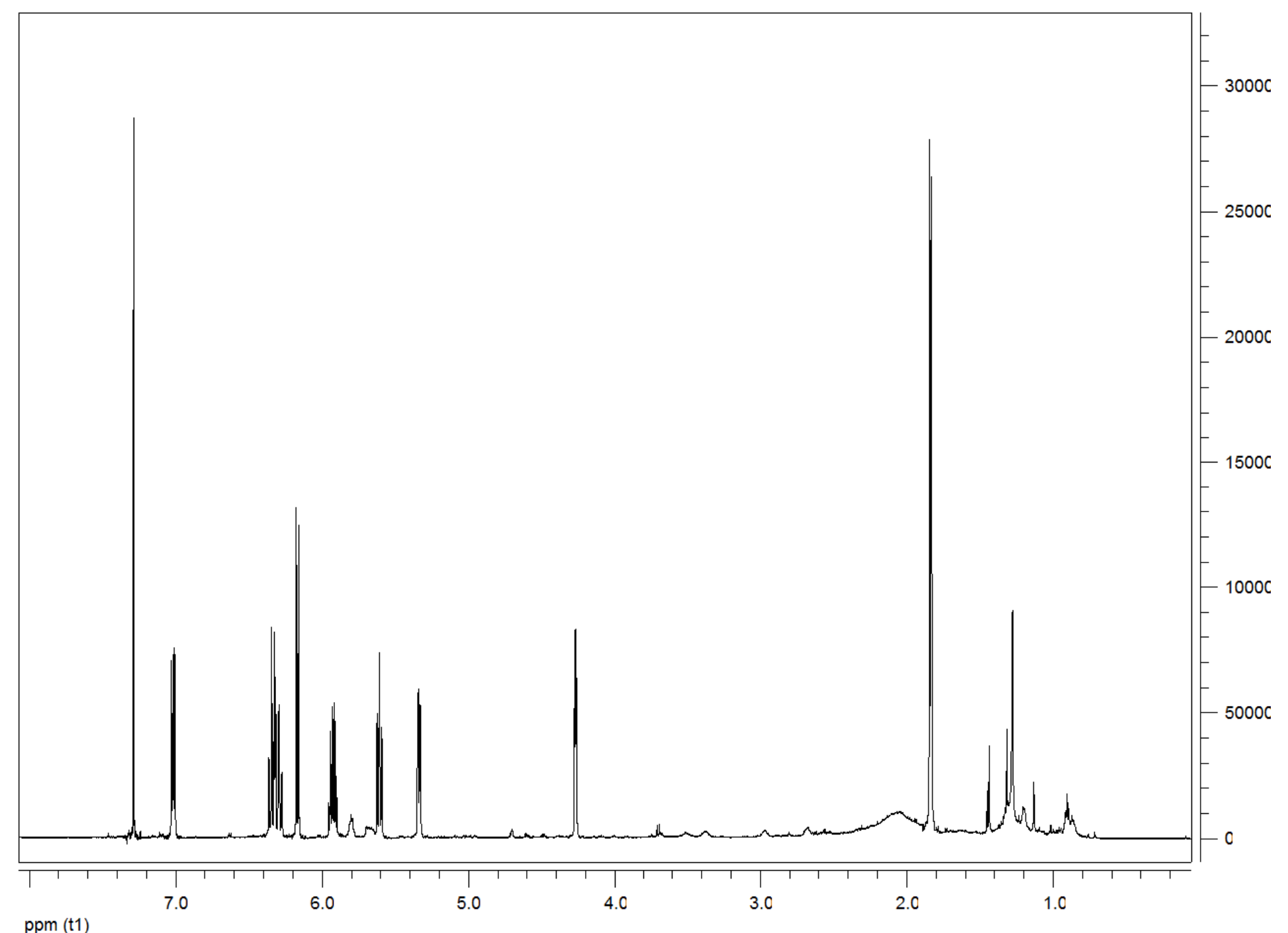


COSY spectrum of diplopyrone B, 2

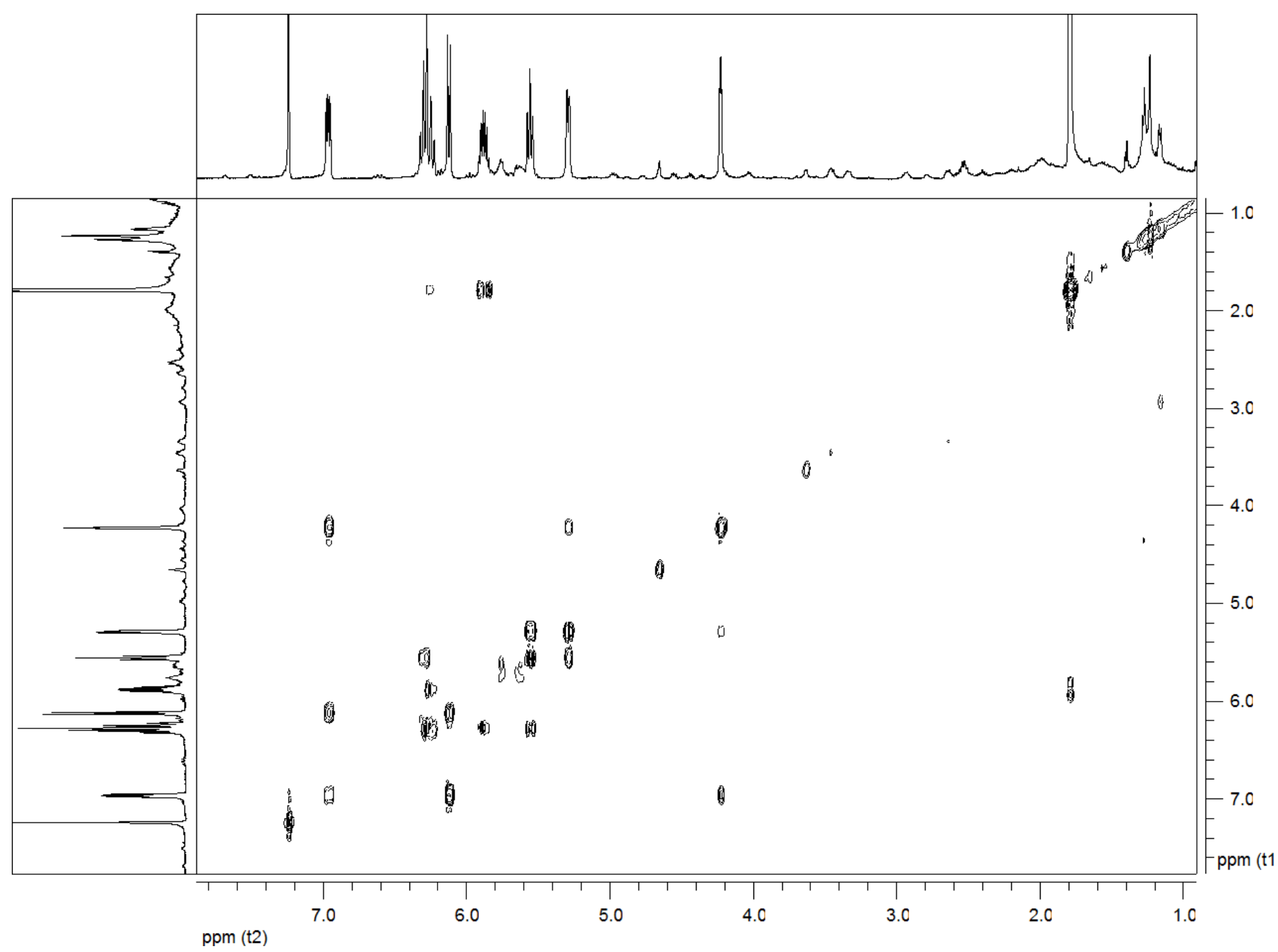


HSQC spectrum of diplopyrone B, 2

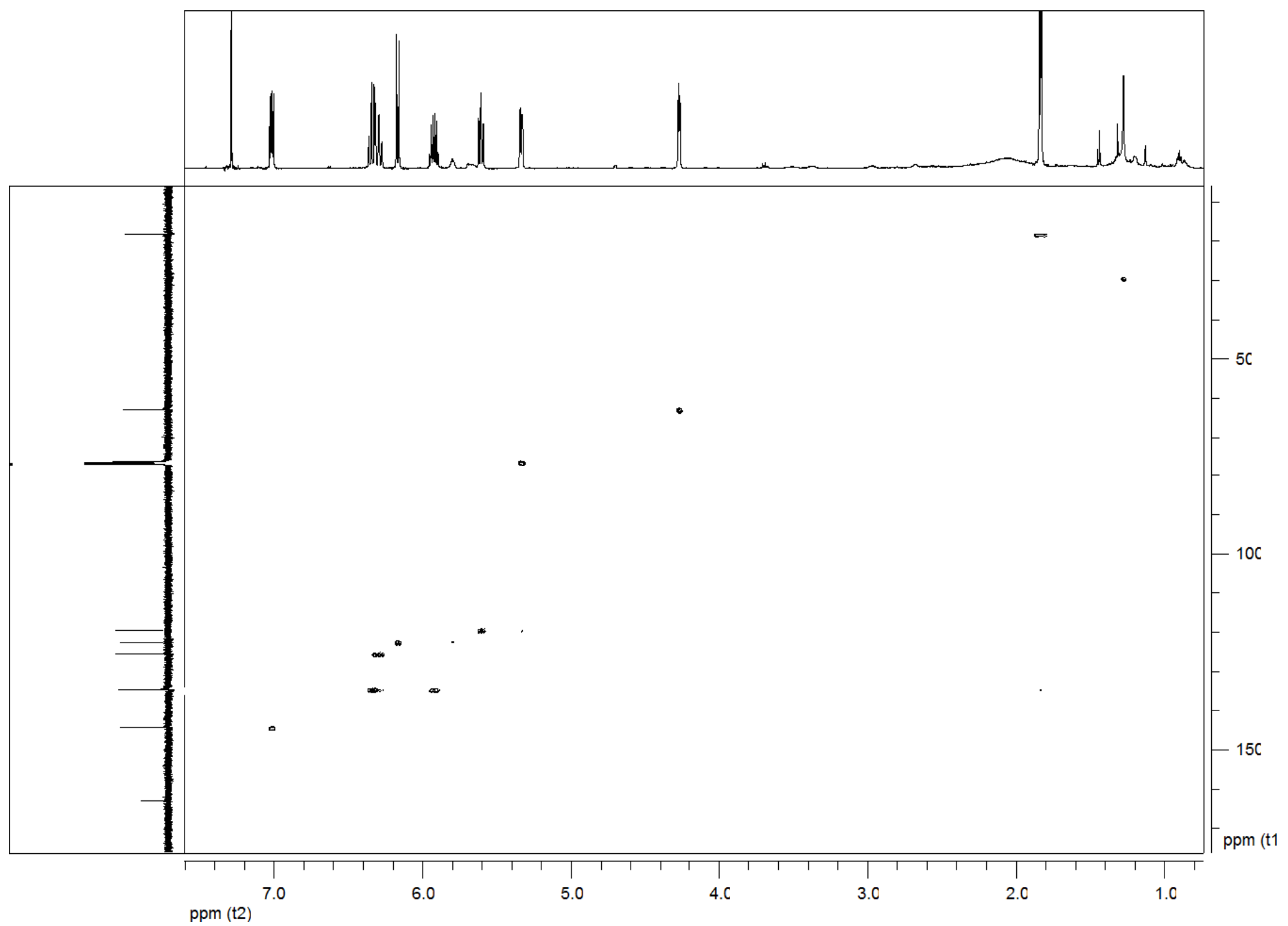


HMBC spectrum of diplopyrone B, 2

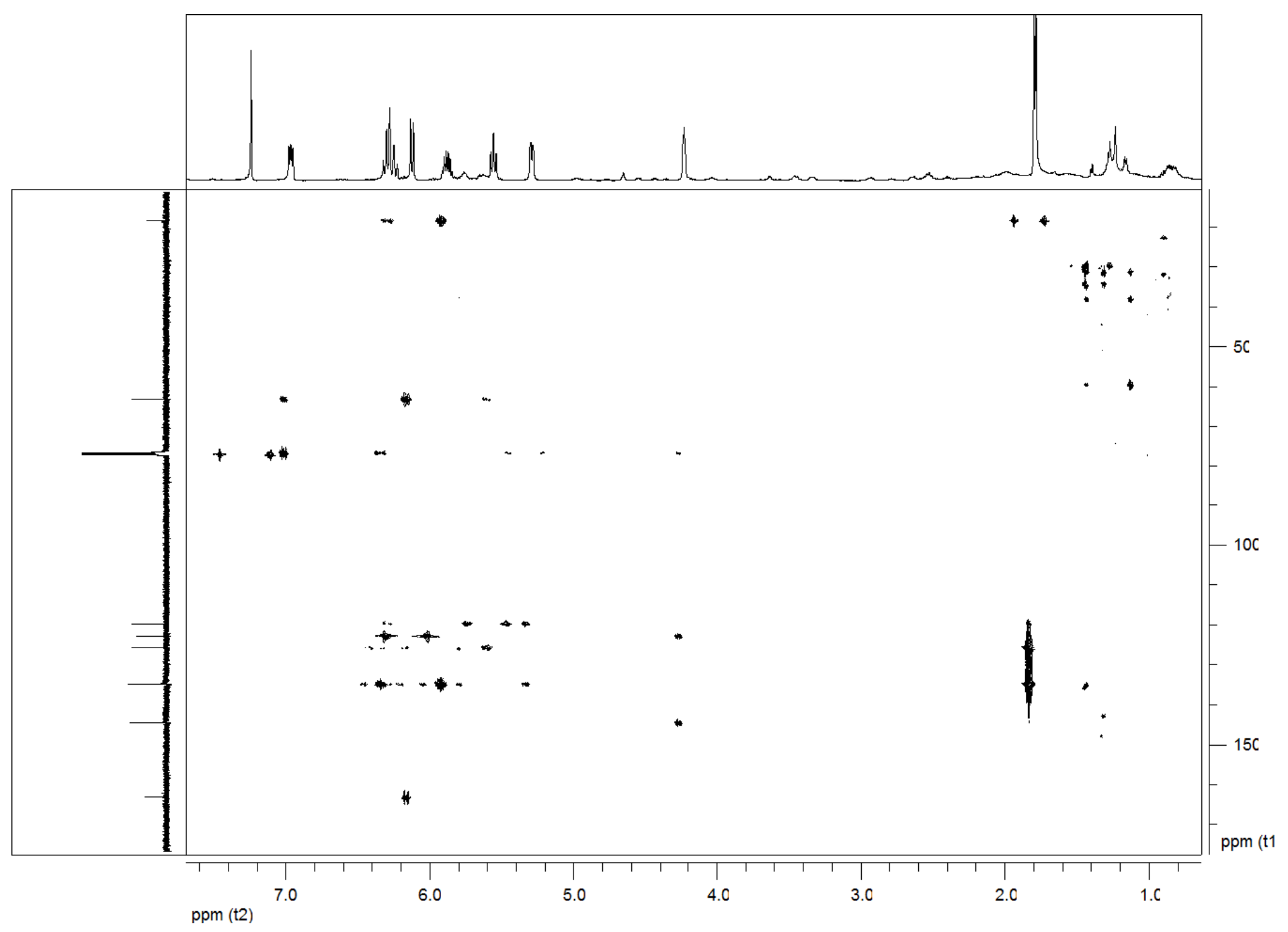


${ }^{13} \mathrm{C}$ NMR spectrum of diplopyrone $\mathrm{B}, \mathbf{2}$

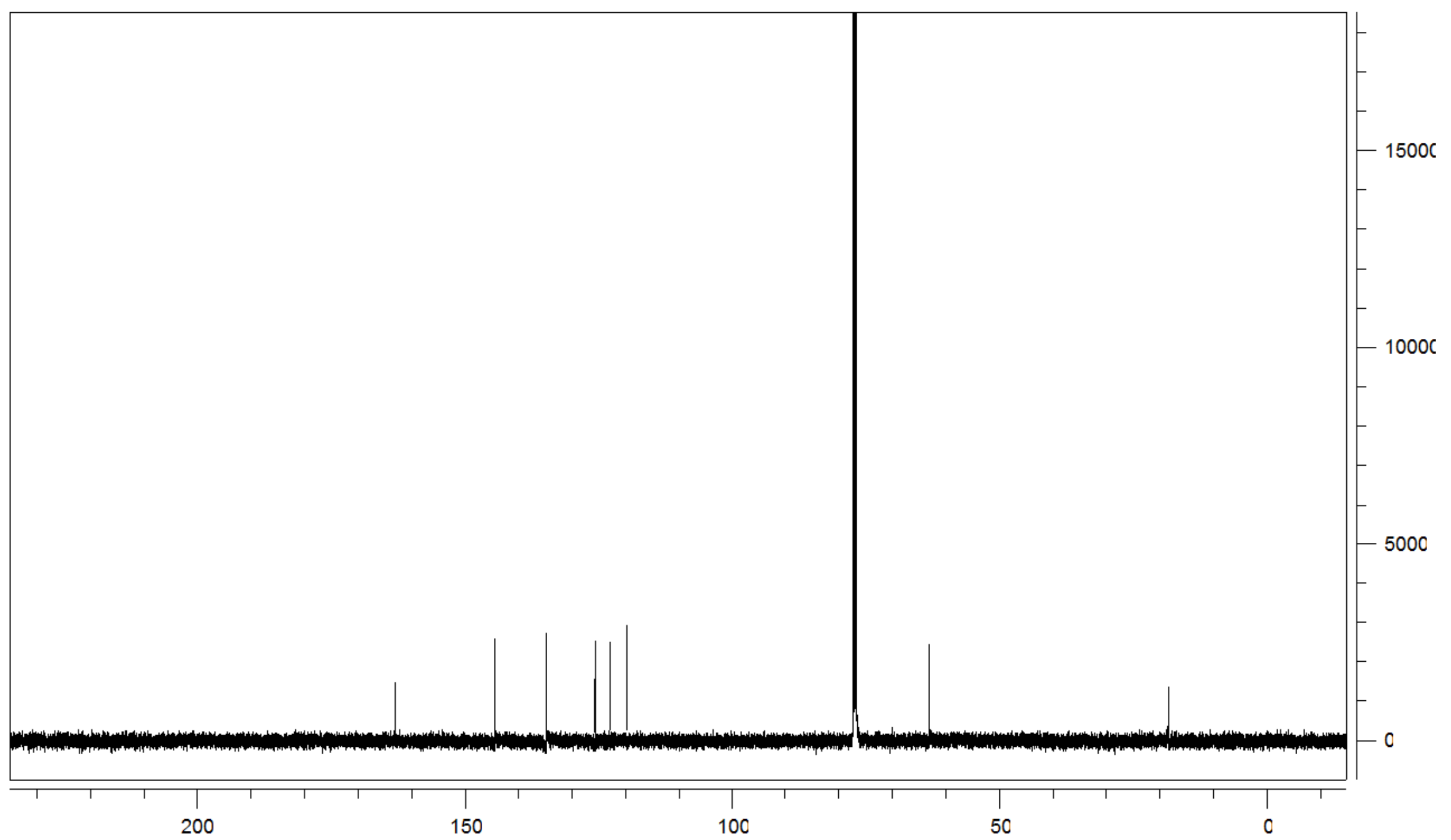

ppm (t1) 
UV spectrum of diplopyrone B, 2

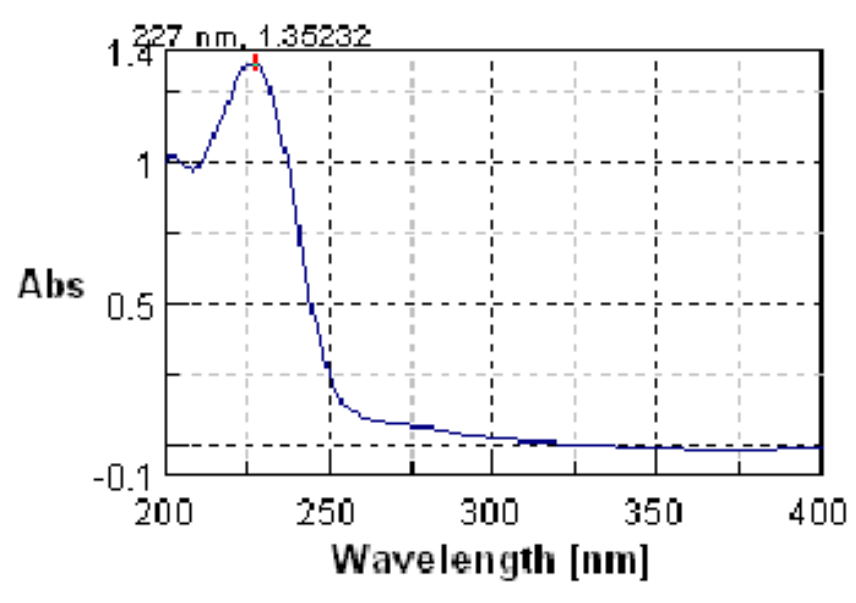


IR spectrum of diplopyrone B, 2

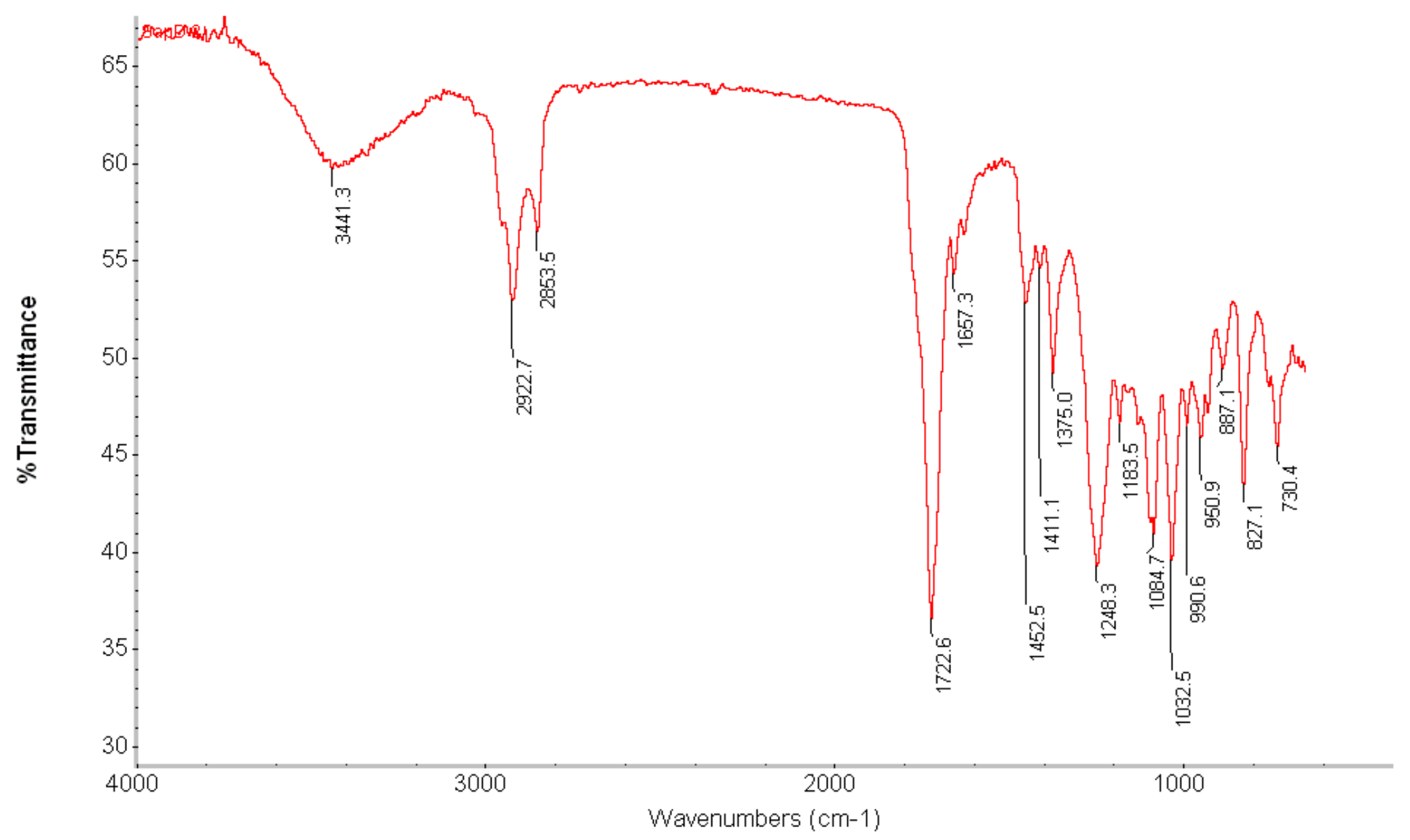


HR ESIMS (+) spectrum of diplopyrone B, 2

DM96_4Cpos \#283-292 RT: $0.99-1.24$ AV: 10 NL: 7.48 E7

T: FTMS + c ESI Full ms [1 00.00-300.00]

$$
\begin{gathered}
203.0677 \\
z=1 \\
\mathrm{C}_{10 \mathrm{H}_{12} \mathrm{O}_{3} \mathrm{Na}}
\end{gathered}
$$

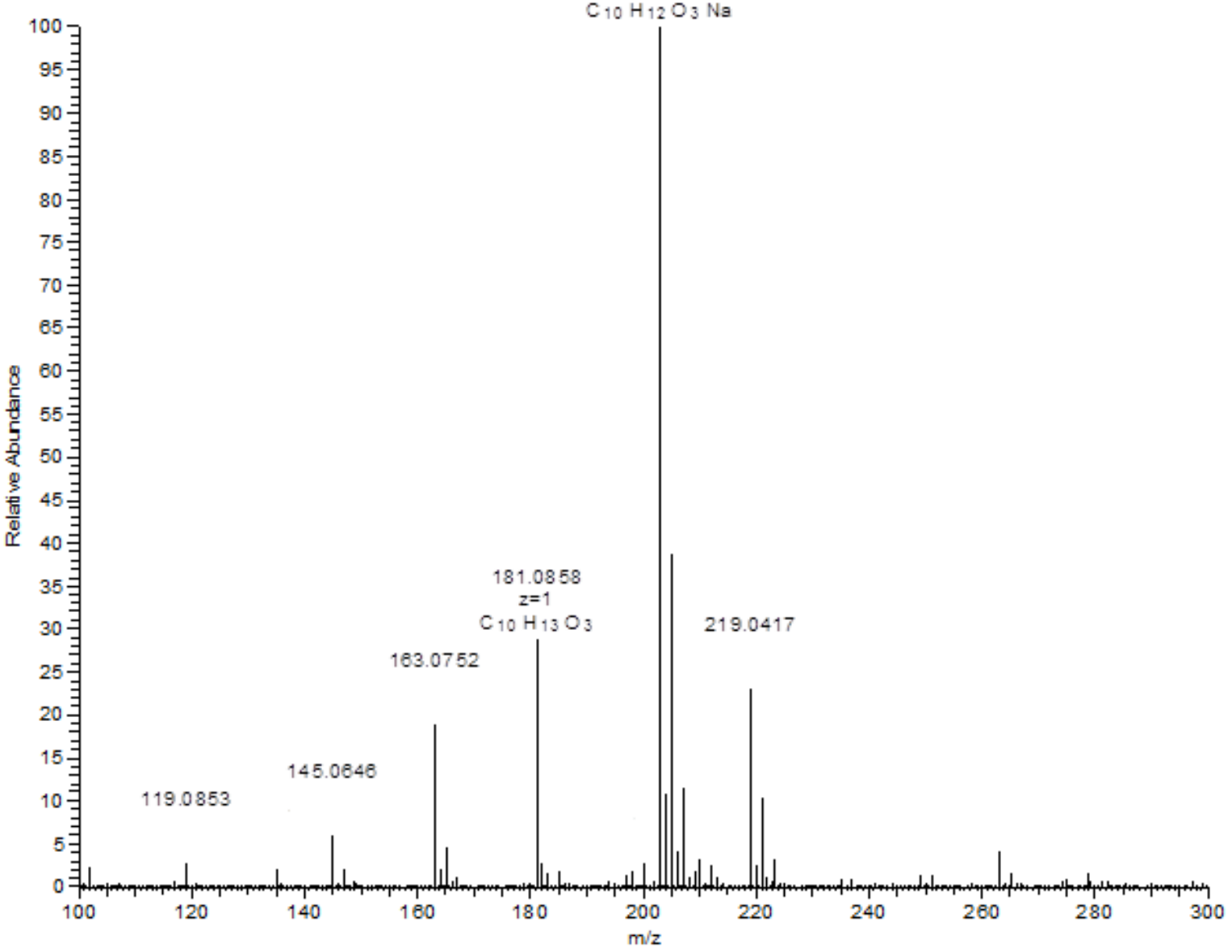


${ }^{1} \mathrm{H}$ NMR spectrum of sapinofuranone D, 3

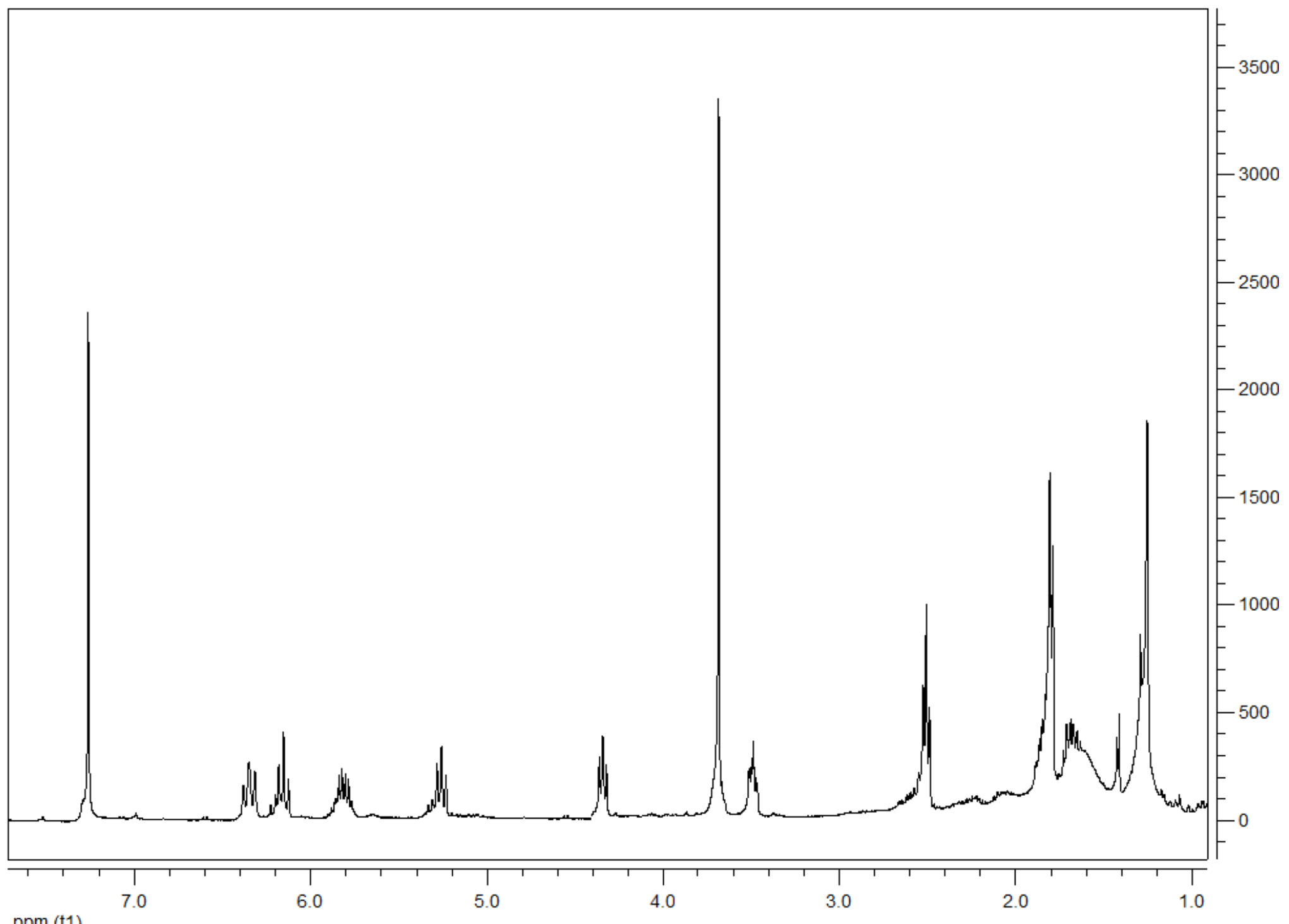

ppm (t1) 
COSY spectrum of sapinofuranone D, $\mathbf{3}$

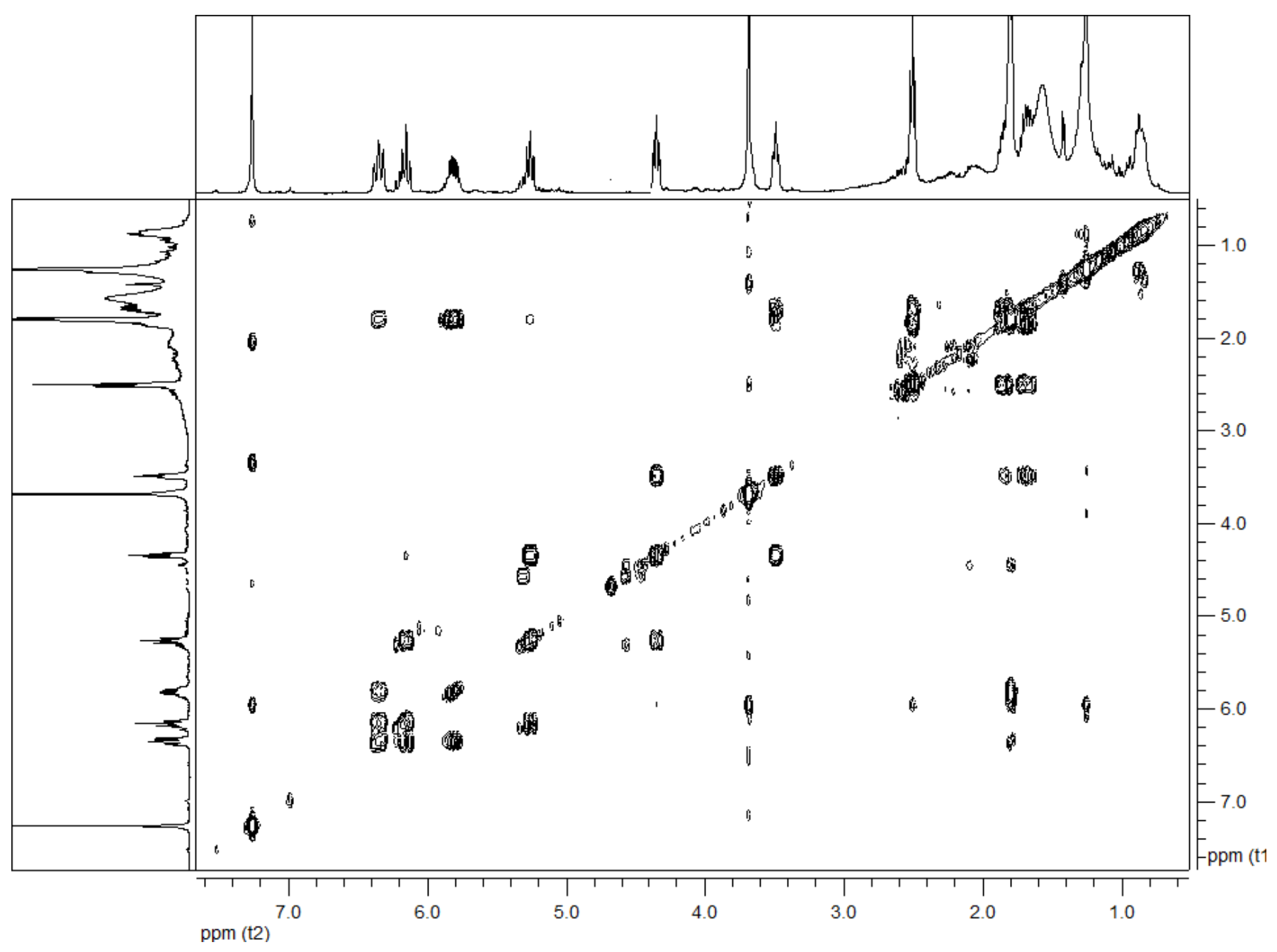


HSQC spectrum of sapinofuranone D, 3

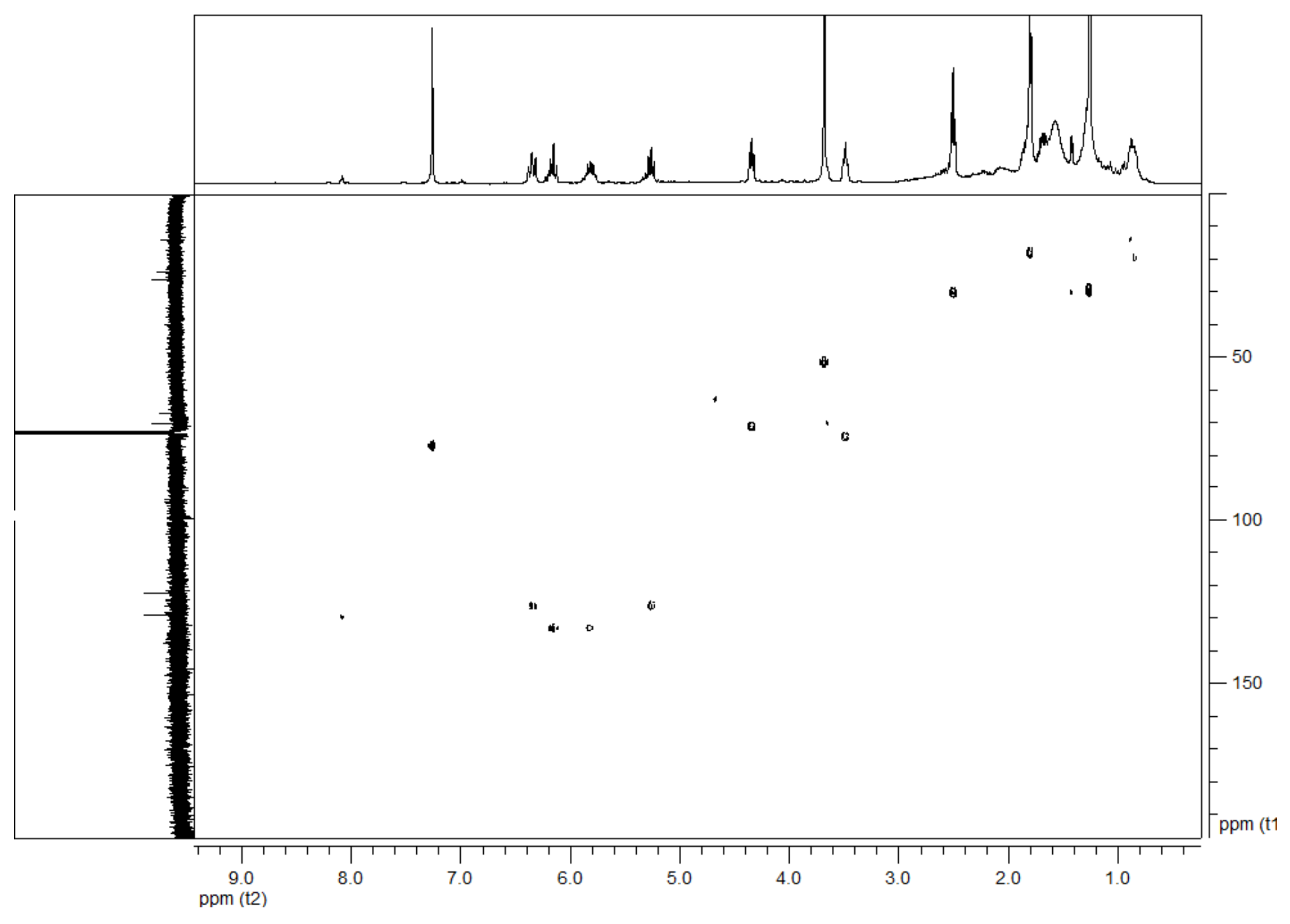


HMBC spectrum of sapinofuranone D, 3

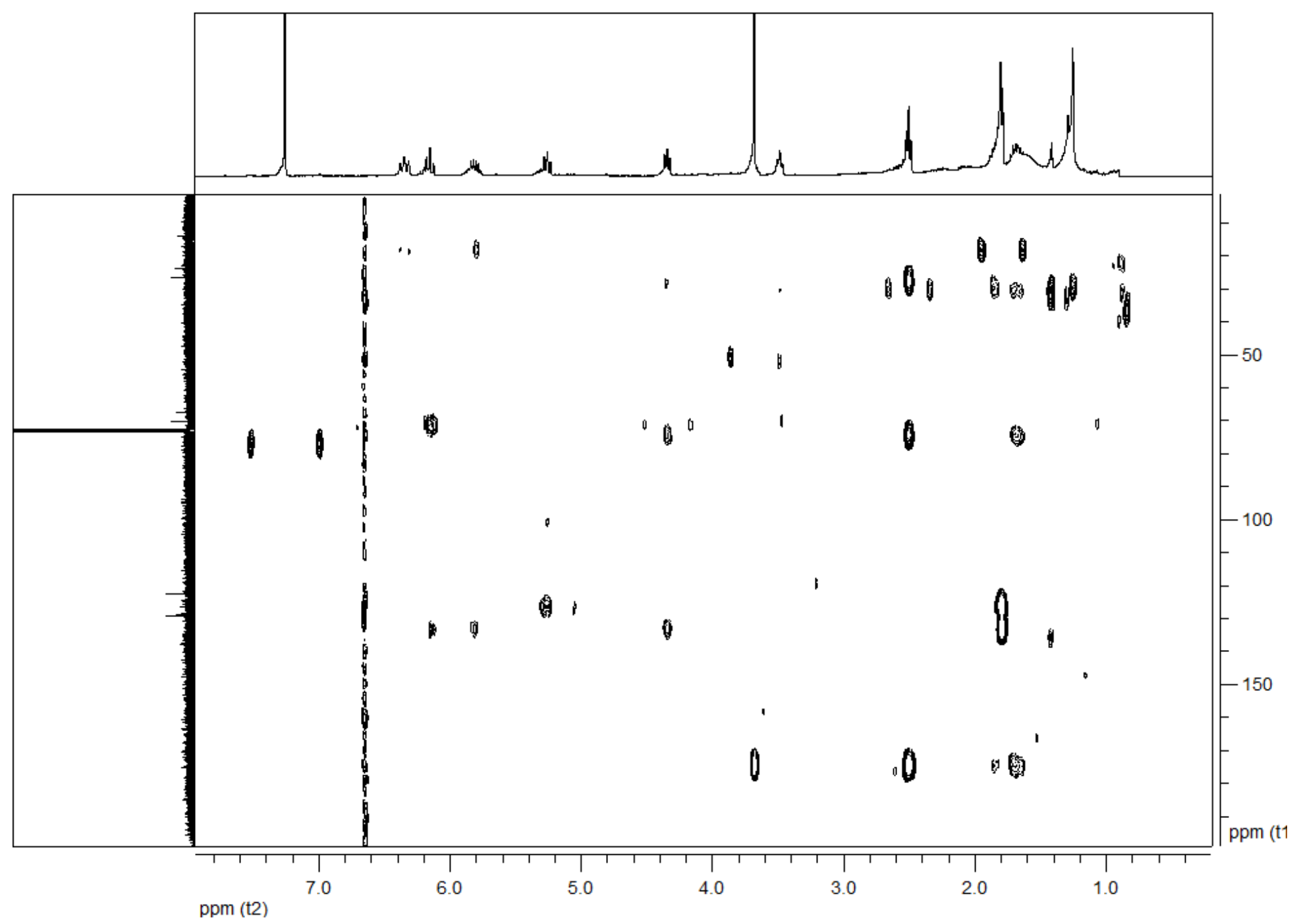


${ }^{13} \mathrm{C}$ NMR spectrum of sapinofuranone $\mathrm{D}, \mathbf{3}$

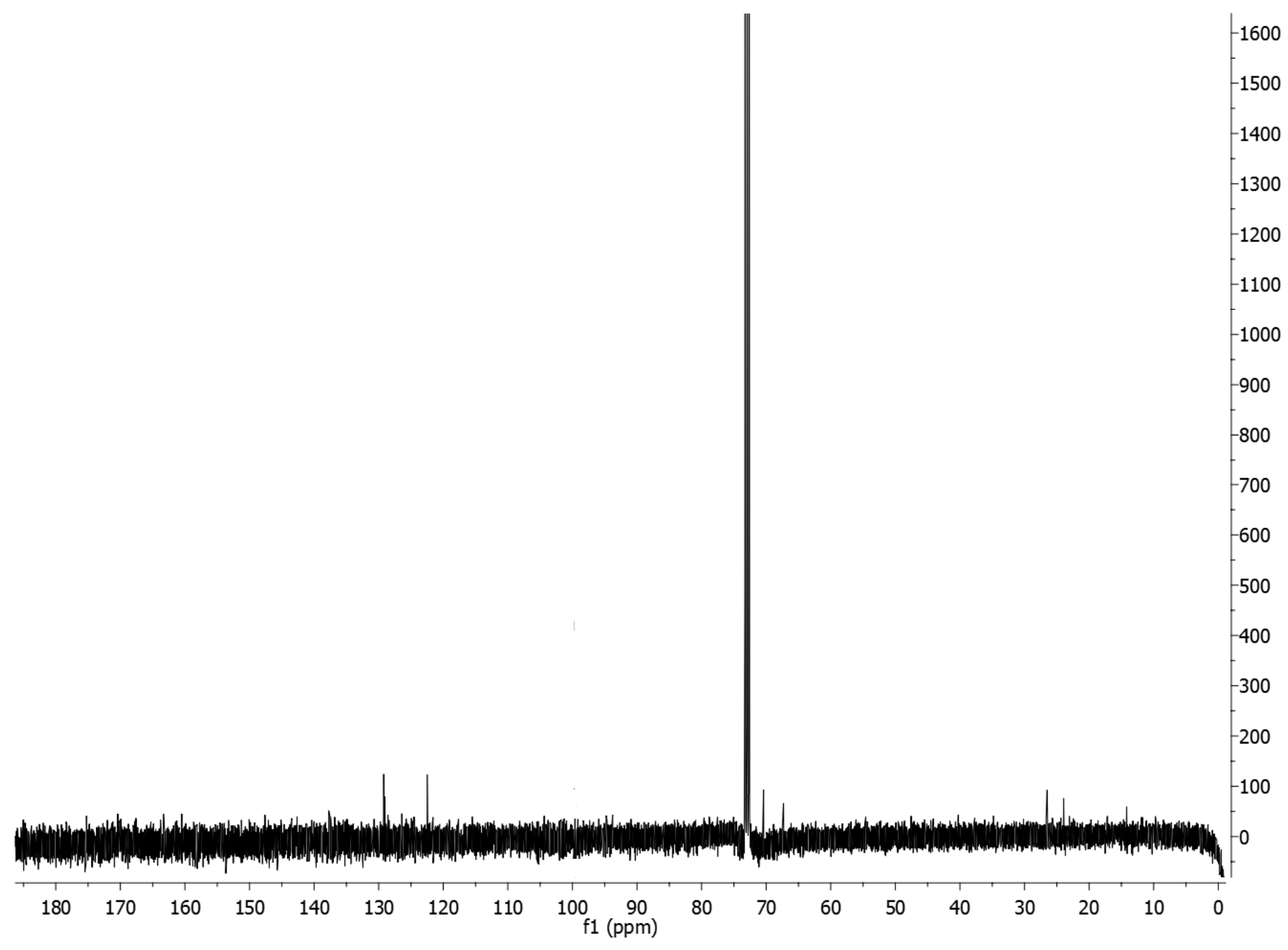


UV spectrum of sapinofuranone $\mathrm{D}, \mathbf{3}$

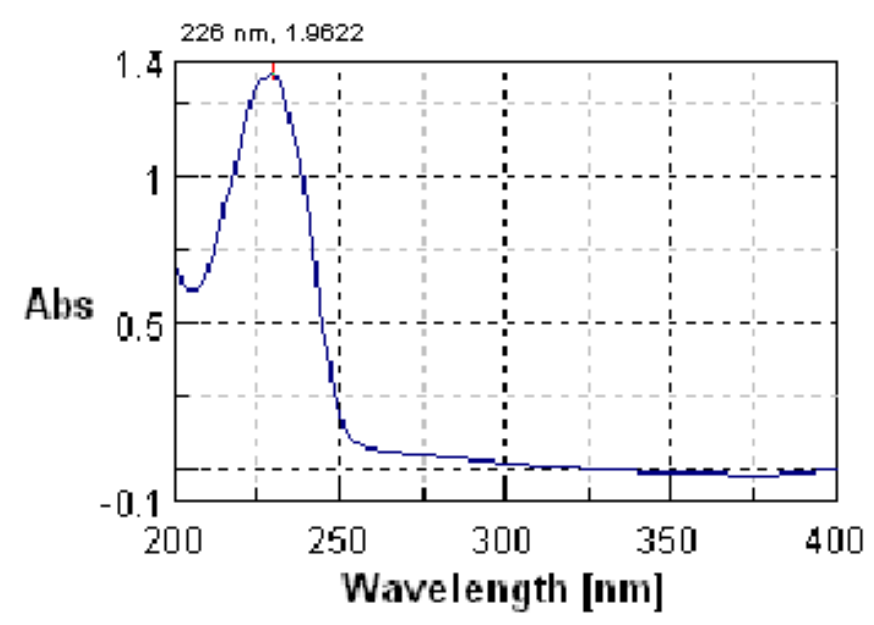


IR spectrum of sapinofuranone D, 3

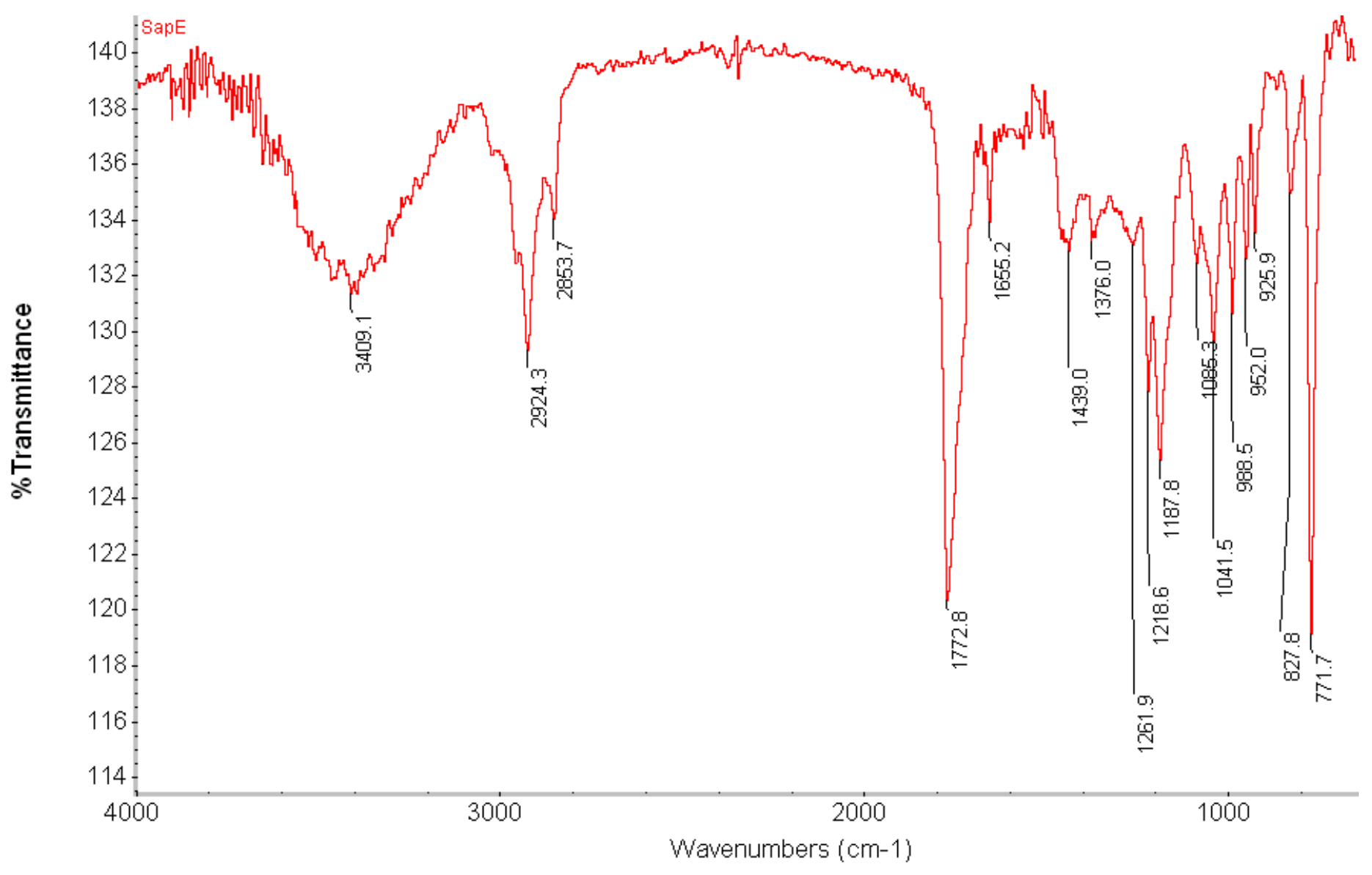




\section{HR ESIMS (+) spectrum of sapinofuranone D, 3}

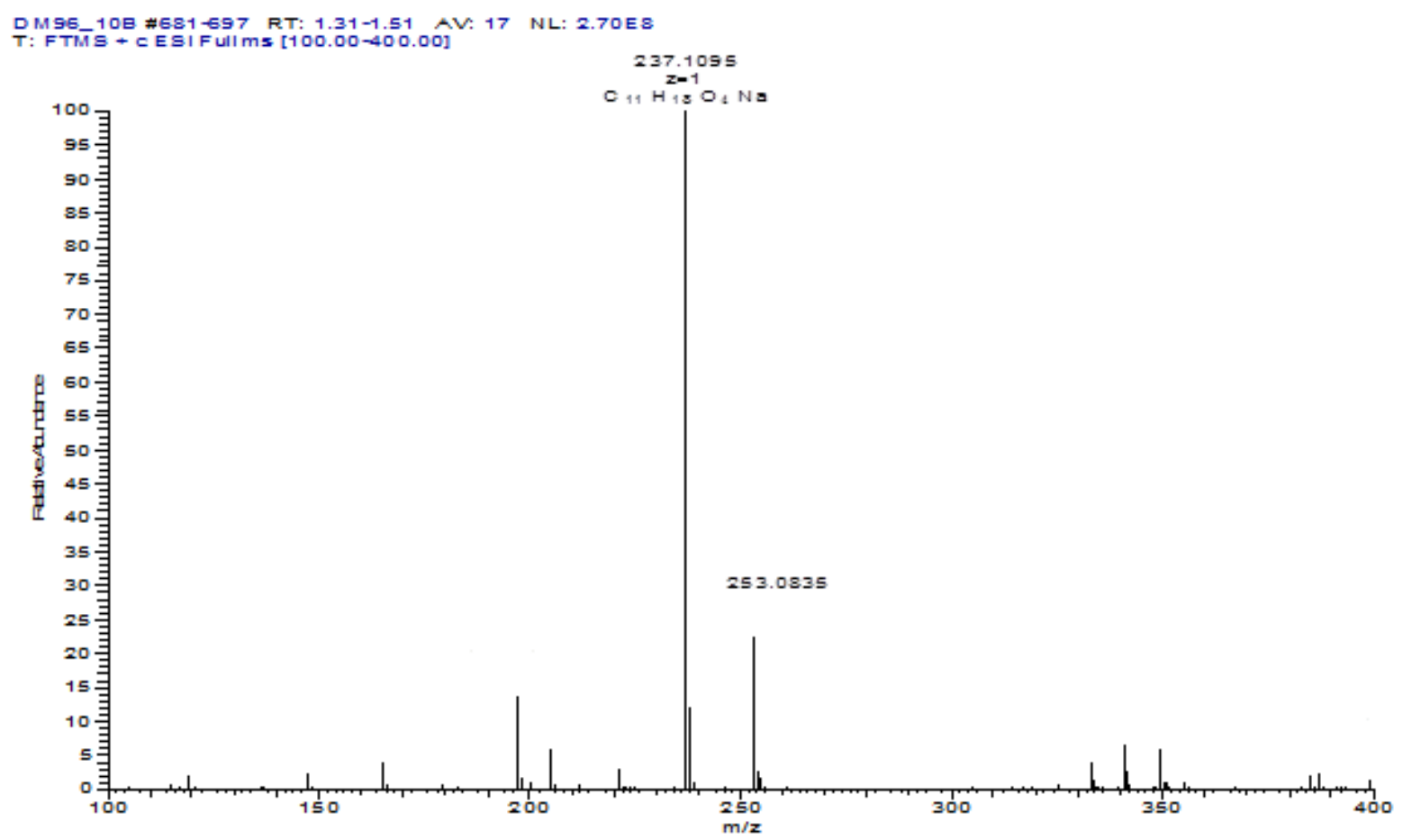


${ }^{1}$ H NMR spectrum of diplobifuranylone C, 4

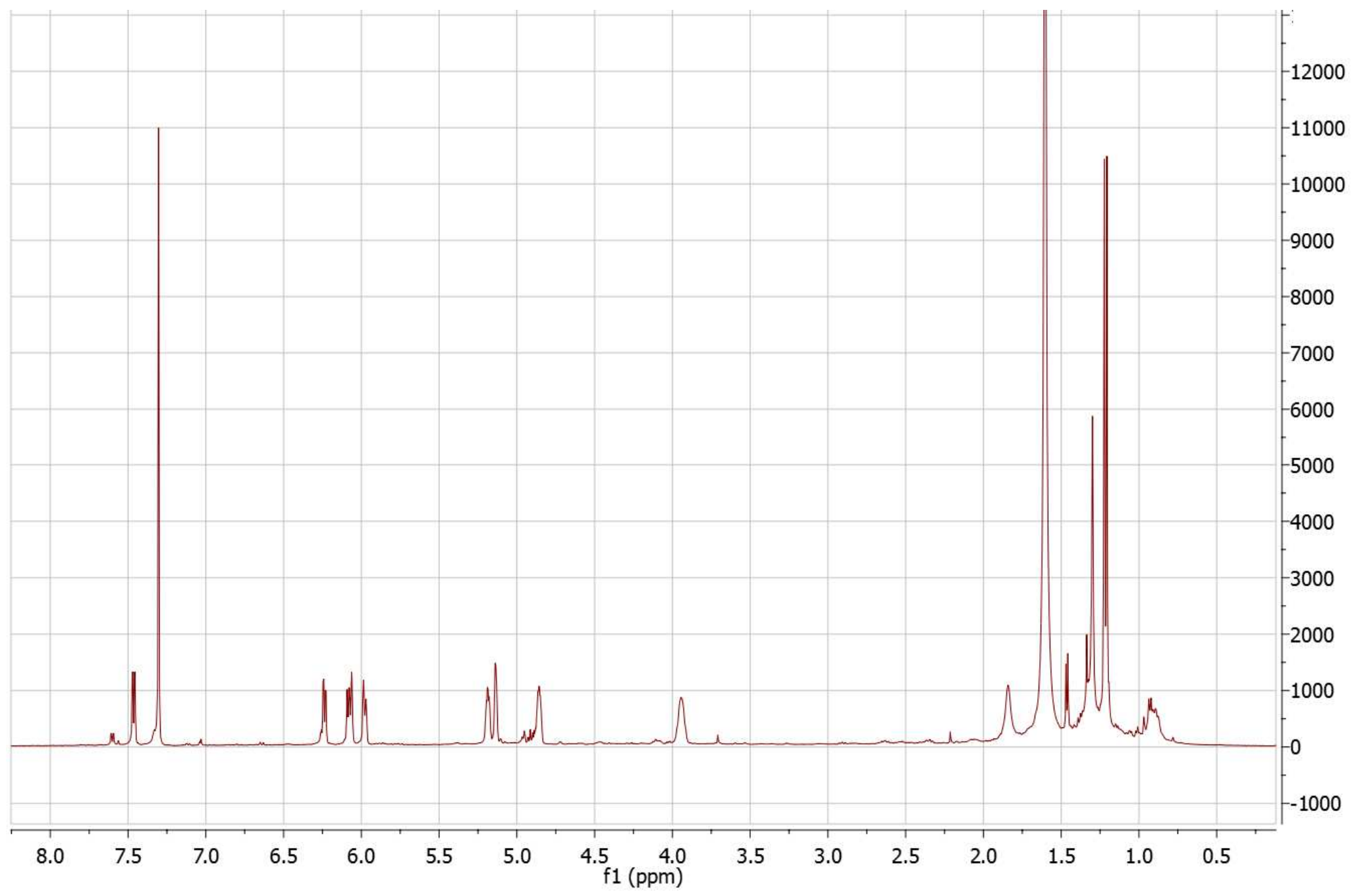


COSY spectrum of diplobifuranylone $\mathrm{C}, \mathbf{4}$

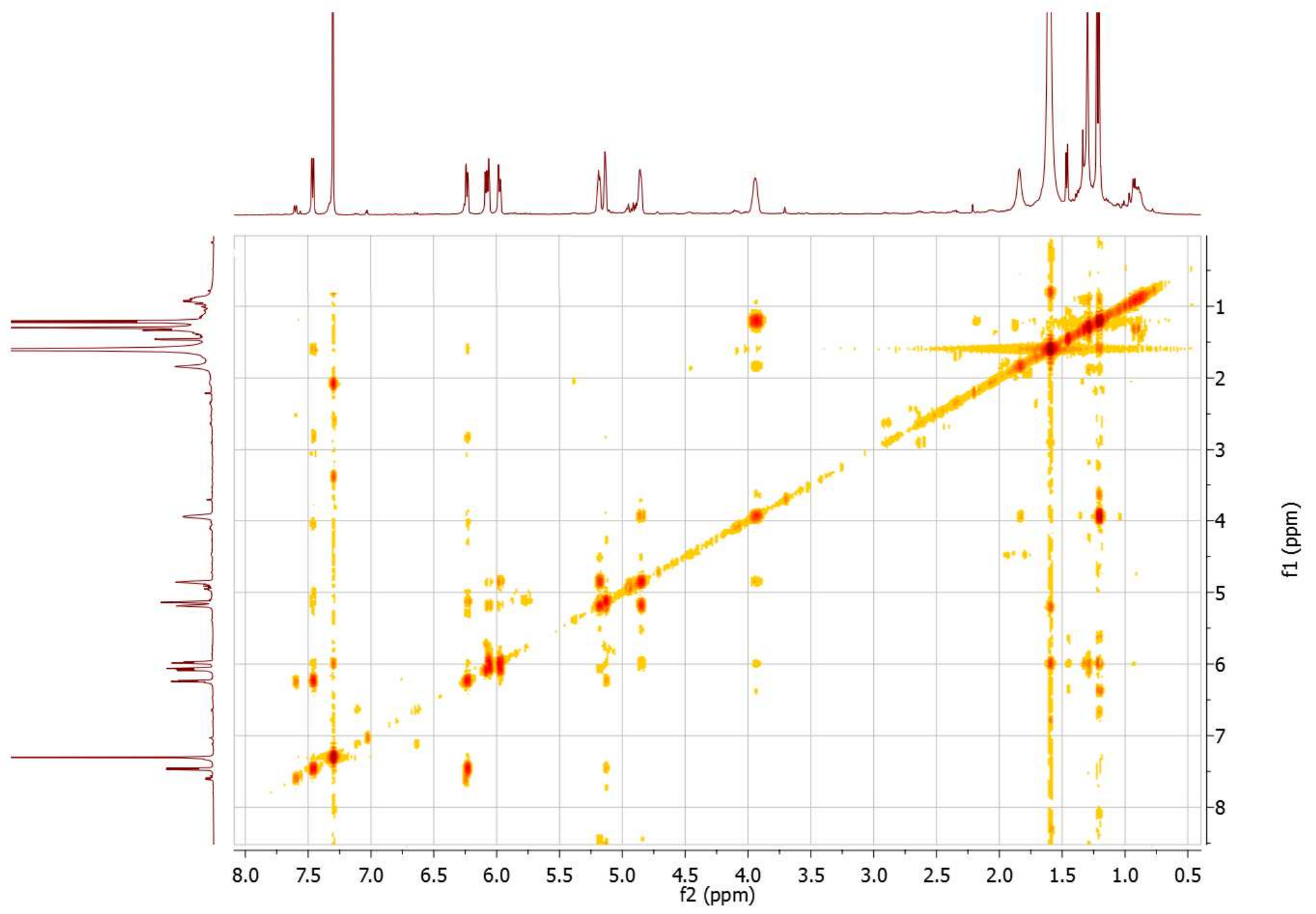


HSQC spectrum of diplobifuranylone C, 4

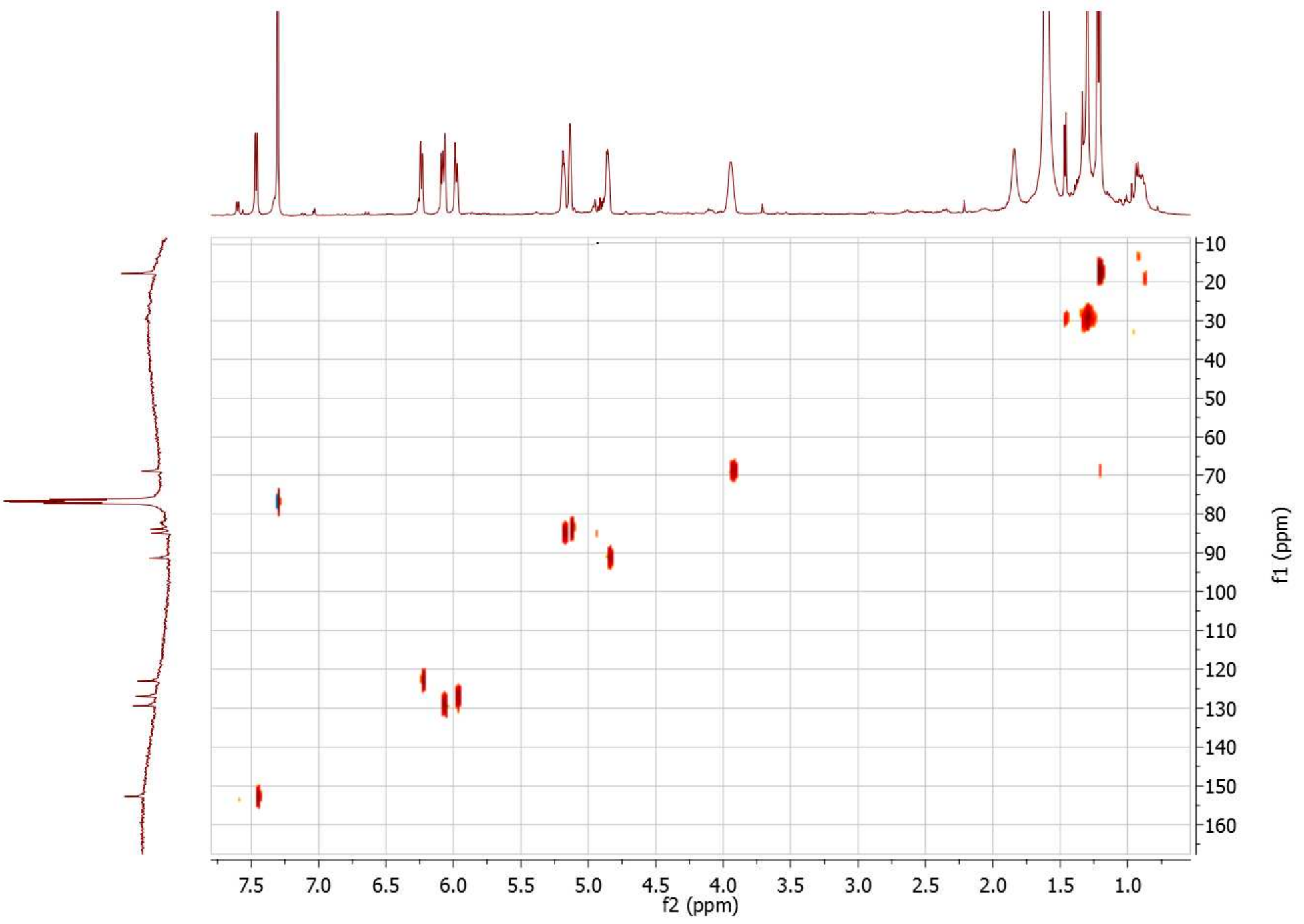


HMBC spectrum of diplobifuranylone $\mathrm{C}, \mathbf{4}$

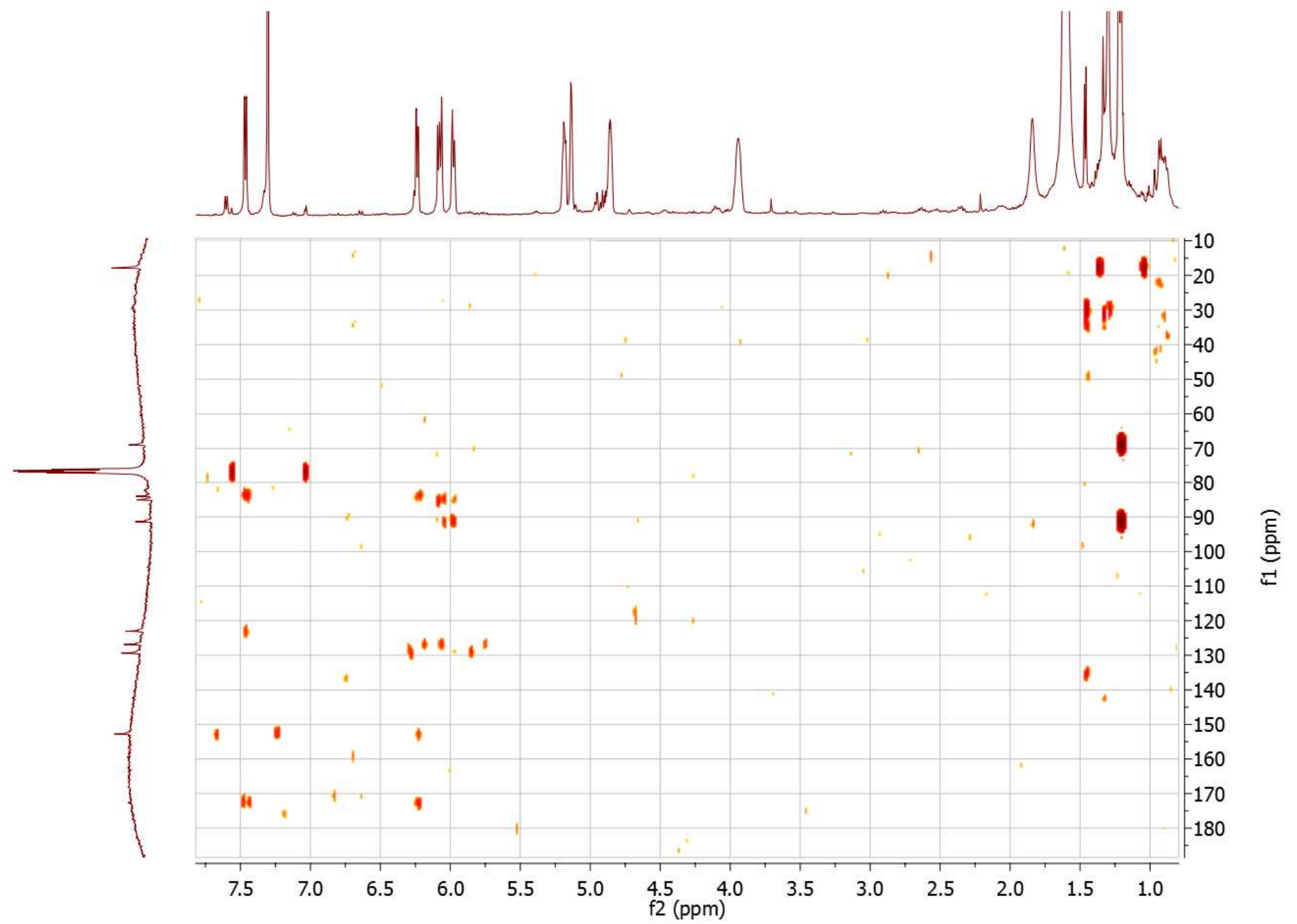


${ }^{13} \mathrm{C}$ NMR spectrum of diplobifuranylone $\mathrm{C}, \mathbf{4}$

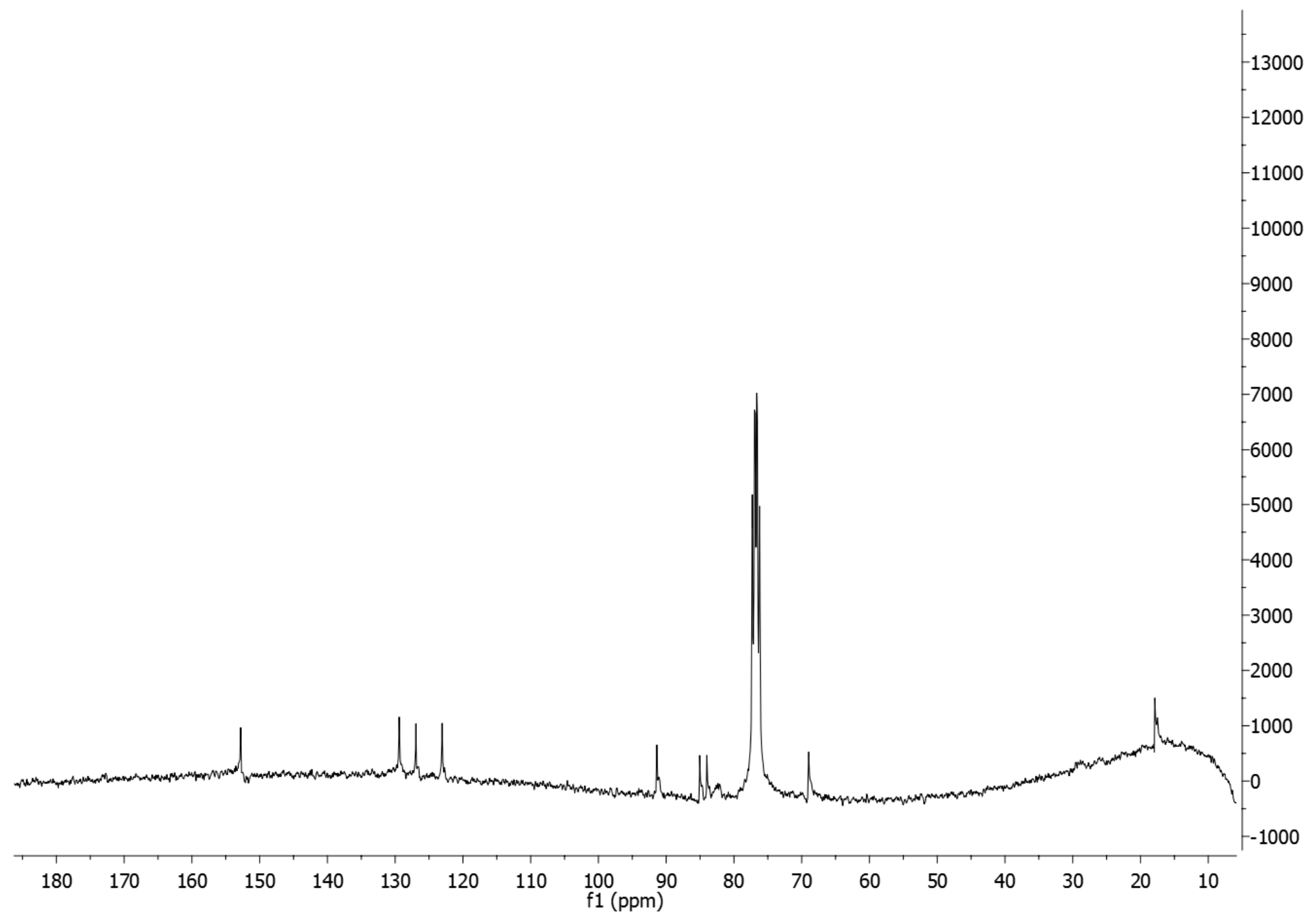


UV spectrum of diplobifuranylone C, 4

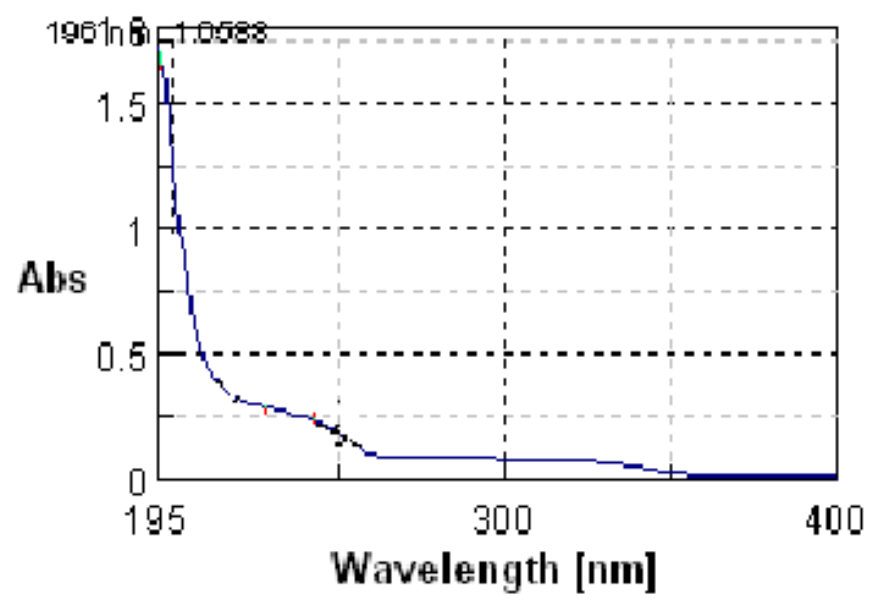


IR spectrum of diplobifuranylone $\mathrm{C}, \mathbf{4}$

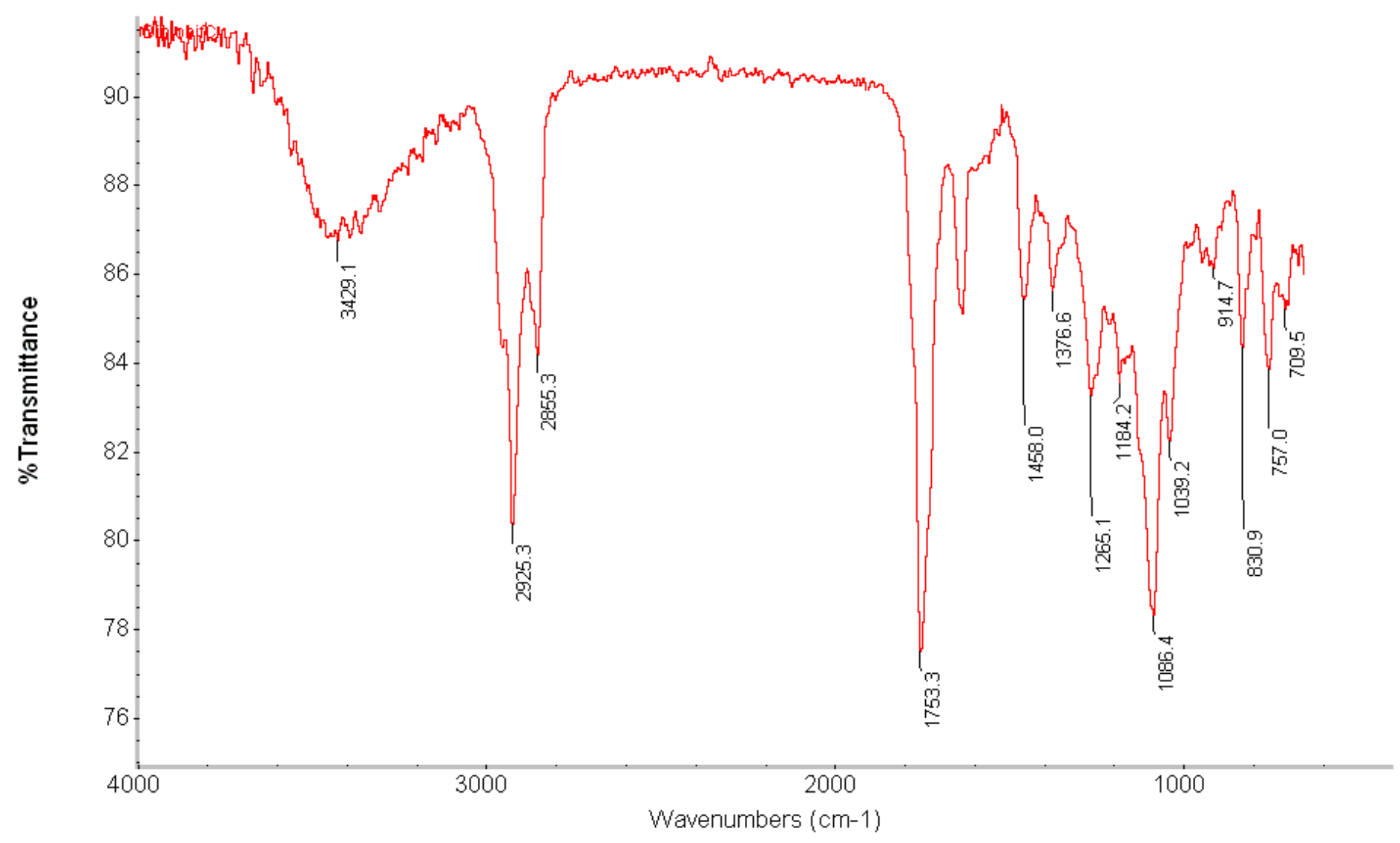


HR ESIMS (+) spectrum of diplobifuranylone C, 4
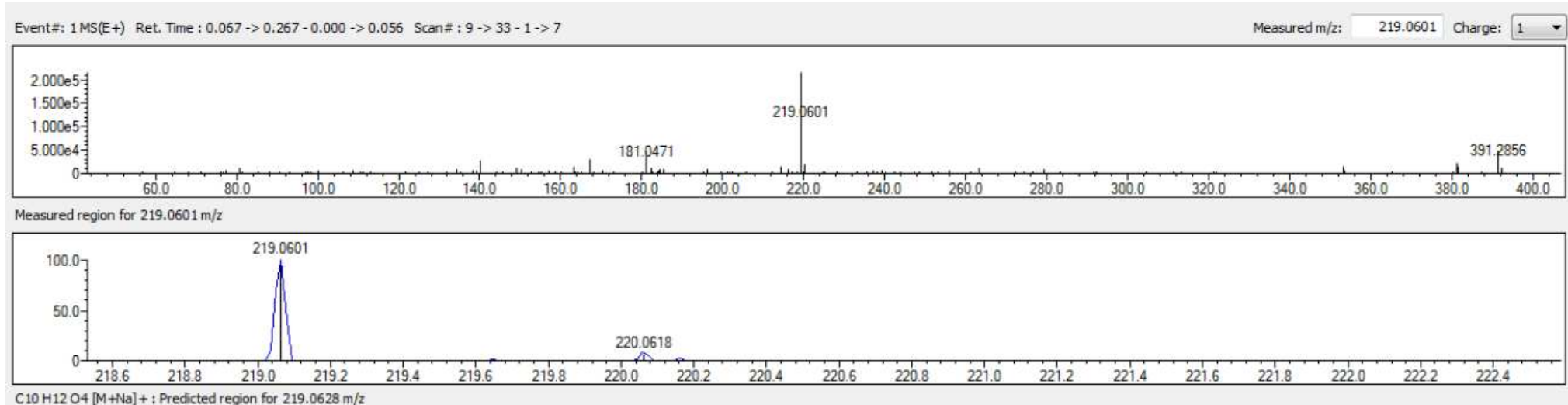

C10 H12 04 [M+Na] +: Predicted region for $219.0628 \mathrm{~m} / 2$

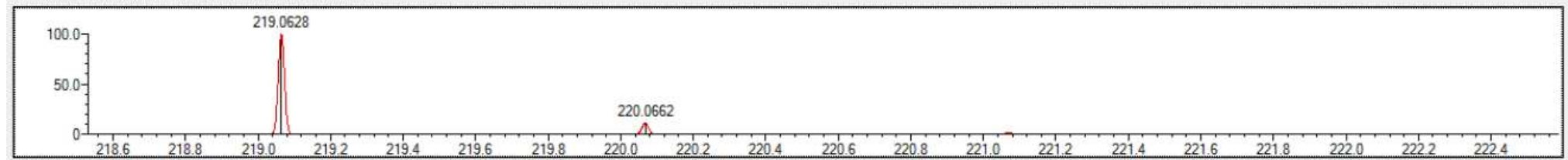

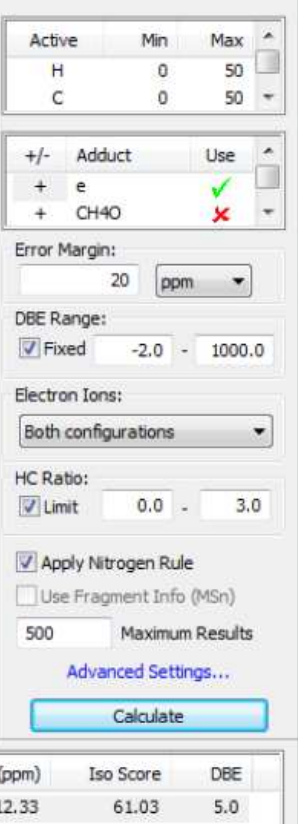

Rank Score Formula (M) Ion

$2 \quad 20.62 \quad \mathrm{C} 10 \mathrm{H} 1204$

$[\mathrm{M}+\mathrm{Na}]+$ 